$$
\text { DOE/PC/9505/ - TI }
$$

\title{
Measurement Techniques For Local and Global Fluid Dynamic Quantities in Two and Three Phase Systems
}

\section{RECEIVED}

\section{TOPICAL REPORT}

\section{FINAL}

DOE Contract $n$ DOE-FC 22-95 PC 95051

S. Kumar, M. P. Duduković

Chemical Reaction Engineering Laboratory

Washington University

St. Louis, MO - 63130

and

B. A. Toseland

Air Products and Chemicals, Inc.

PO Box 25780

Lehigh Valley, PA 18007

March, 1996

Cleared by Potent Counsel WSAOE PATENTELEARANCE IS REQUIRED PRIOR TO FIE PUALEATIONOFTHS DOEYMENT.

\section{DEC 111996}

\section{OSTI}

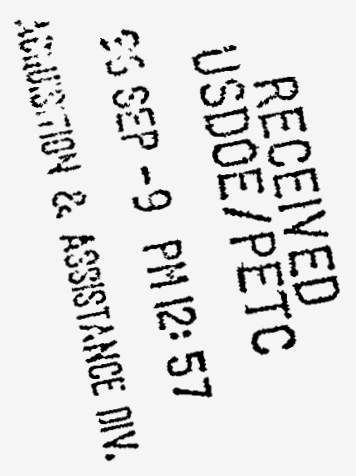




\section{DISCLAIMER}

Portions of this document may be illegible in electronic image products. Images are produced from the best available original document. 


\section{DISCLAIMER}

This report was prepared as an account of work sponsored by an agency of the United States Government. Neither the United States Government nor any agency thereof, nor any of their employees, makes any warranty, express or implied, or assumes any legal liability or responsibility for the accuracy, completeness, or usefulness of any information, apparatus, product, or process disclosed, or represents that its use would not infringe privately owned rights. Reference herein to any specific commercial product, process, or service by trade name, trademark, manufacturer, or otherwise does not necessarily constitute or imply its endorsement, recommendation, or favoring by the United States Government or any agency thereof. The views and opinions of authors expressed herein do not necessarily state or reflect those of the United States Government or any agency thereof. 


\title{
Measurement Techniques For Local and Global Fluid Dynamic Quantities in Two and Three Phase Systems
}

\section{TOPICAL REPORT}

\author{
FINAL
}

DOE Contract DOE-FC 22-95 PC 95051

S. Kumar, M. P. Duduković

Chemical Reaction Engineering Laboratory

Washington University

St. Louis, MO - 63130

and

B. A. Toseland

Air Products and Chemicals, Inc.

PO Box 25780

Lehigh Valley, PA 18007

March, 1996

USYDOE PATENT GLEARANCELS REQUIRED RRIØK TO

THE PUBLICA

eleared by petcut corrser. 


\section{Contents}

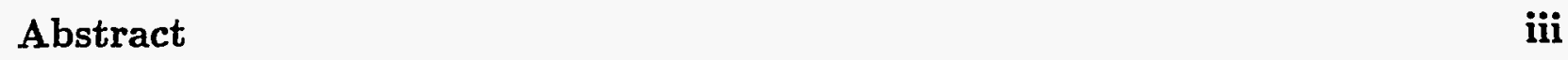

Executive Summary $\quad$ iv

1 Introduction $\quad 1$

2 Gas Holdup and Solids Concentration Measurement 1

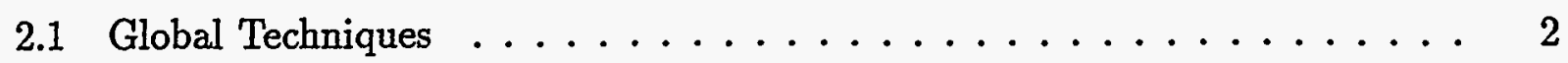

2.2 Line Average Measurements based on Radiation Techniques . . . . . . . 6

2.3 Probes for Local Gas Holdup and Solids Concentration Measurement . . . 16

2.3.1 Impedance Probes . . . . . . . . . . . . . . . 16

2.3 .2 Optical Probes . . . . . . . . . . . . . . . . . . 19

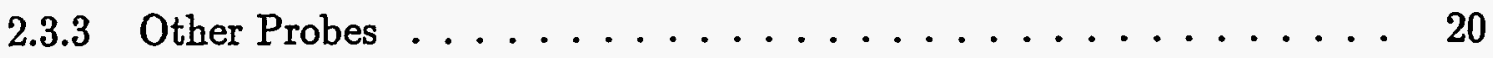

3 Measurement of Bubble Sizes and Velocity 22

4 Measurement of Liquid and Solid Velocities 29

5 Final Recommendations and Remarks $\quad \mathbf{3 7}$

6 Nomenclature $\quad 39.40$

7 References $\quad 4142$ 


\begin{abstract}
Available measurement techniques for evaluation of global and local phase holdups, instantaneous and average phase velocities and for the determination of bubble sizes in gas-liquid and gas-liquid-solid systems are reviewed. Advantages and disadvantages of various techniques are discussed. Particular emphasis is placed on identifying methods that can be employed on large scale, thick wall, high pressure and high temperature reactors used in the manufacture of fuels and chemicals from synthesis gas and its derivatives.
\end{abstract}




\section{Executive Summary}

This report presents a critical review of the methods available for assessing the fluid dynamic parameters in large industrial two and three phase bubble column and slurry bubble column reactors operated at high pressure and temperature. The physical principles behind various methods are explained, and the basic design of the instrumentation needed to implement each measurement principle is discussed. Fluid dynamic properties of interest are : gas, liquid and solids holdup and their axial and radial distribution as well as the velocity distribution of the two (bubble column) or three phases (slurry bubble column). This information on operating pilot plant and plant reactors is essential to verify the computational fluid dynamic codes as well as scale-up rules used in reactor design. Without such information extensive and costly scale-up to large reactors that exploit syngas chemistries, and other reactors in production of fuels and chemicals, cannot be avoided. The fluid dynamic parameters mentioned above must be measured under operating conditions in large units and the data used for evaluating existing models.

The findings of this study can be summarized as follows. While many promising techniques based on conductance, impedance, ultrasound, light transmittance and other principles are emerging, none has yet reached the status of being capable of providing reliable measurements in high temperature, high pressure, large diameter columns operated in the churn turbulent regime with high gas and solids holdup. Hence, further development of these techniques in the laboratory should be encouraged.

The following methods seem most suitable at the moment for providing the fluid dynamic parameters in industrial columns such as the Laporte AFDU reactor.

For global gas holdup measurements, determination of the dynamic height of the slurry in an operating reactor (by a gamma ray or other means) and of the settled slurry in the absence of gas provides the least ambigous value of overall gas holdup. During shut down the dynamic gas disengagement technique is capable of providing global information on the existence of unimodal or multimodal bubble size distribution. Overall solids holdup can be determined from the volume of the solids loaded and the height (volume) of the slurry at operating conditions.

Best estimates of gas holdup during operation, and its distribution along the column height, can be obtained via sectional pressure drop measurements. This estimate requires the knowledge of the solids concentration distribution which is not always available.

Density profiles along the column can be obtained by gamma ray densitometry (a needed correction for obtaining proper cross sectional values from the usually measured chordal averages is discussed in this report). Cross-sectional density distribution can be readily obtained 
by gamma ray tomography. Obtaining gas holdup profiles along the column height, or in a cross section, again requires information (or assumptions) regarding solids concentration distribution. Solids concentration profiles can be obtained noninvasively by dual beam gamma ray tomography using sources with photon emissions at two different energy levels. This may require excessive scanning times. Invasive isokinetic sampling or point conductance probes represent the unappealing alternative in hot and high pressure systems for the measurement of local velocity and/or phase concentration. Ultrasound probes deserve further attention and can be suitably designed to provide local measurements of phase concentrations.

While sophisticated techniques such as Particle Image Velocimetry (PIV) and Computer Aided Radioactive Particle Tracking (CARPT) can be used in the laboratory to map the velocity fields, at present their use in industrial reactors is not possible. To determine liquid velocities, pitot tubes seem to be still favored, while gas (bubble) velocities can be assessed by multipoint optical probes. How well these can work in systems with high solids loading remains to be demonstrated. Only CARPT is capable of determining solids velocities at high solids holdup, and this, unfortunately, cannot be implemented for large reactors.

Specific recommendations for the Laporte reactor can be summarized as follows :

1. Continue to use gamma densitometry and implement gamma ray tomography for noninvasively obtaining density distributions along and across the column at all operating conditions.

2. Develop if possible dual beam densitometry by adding the Am-241 or Co-60 source to the current Cs- 137 source. This would enable one to resolve the gas, liquid and solids holdup profiles in the column at all operating conditions.

3. Install additional pressure taps for the measurement of sectional pressure drop along the column, and also monitor pressure fluctuations and compute cross-correlations between various points.

4. Prior to each shut down execute the dynamic gas disengagement method and evaluate the bubble size distribution.

5. Consider installing invasive probes for the estimation of phase velocities. Pitot tube, five point optical probes and heat transfer probes are the current likely candidates. 


\section{Introduction}

Design and scale-up of bubble columns, slurry bubble columns, three phase fluidized beds and other multiphase systems are still predominantly based on empirical correlations validated over a limited range of operating conditions and physical properties. Application of more fundamental fluid dynamic models awaits their experimental verification. Hence, measurement of fluid dynamic quantities such as phase velocities, phase holdups, bubble size etc. are of great interest both for extending the range of validity of current correlations and for verification of fundamental hydrodynamic models. Measurement is also important in interpreting, understanding and predicting reactor performance. Advances in instrumentation and signal processing techniques have led to a rapid proliferation of the available experimental methods for measurements in multiphase flows. There are a number of good reviews of these methods in the literature including those by Banerjee and Lahey (1981), Delhaye (1986), Jones and Delhaye (1976), Snoek (1990) and Lubbert, (1991) to mention a few.

An attempt is made here to present a comprehensive review of the experimental methods available for multiphase systems. The emphasis is on techniques that can be utilized under conditions of interest in practice such as high pressure and temperature, large solids holdup etc. The measurement methods for the determination of the following quantities are considered :

- Void fraction and solids concentration;

- Bubble size distribution and rise velocities;

- Liquid and solid phase velocities.

\section{Gas Holdup and Solids Concentration Measurement}

Gas holdup and solids concentration measurement methods can be broadly classified into two categories : (1) those providing an overall or global measurement and (2) those that provide a local or point measurement. The global measuring techniques yield information on the line, area or volume averaged gas or solids holdup. The volume averaged or overall fractional holdup of a phase is defined as the fraction of the volume of the multiphase dispersion that is occupied by that phase. In general, the measurement of the overall holdup is relatively simple. It provides information regarding what fraction of the system volume is occupied by the phase of interest. Measurement of the phase fraction at a point is in itself not of much use unless the distribution of such point measurements is obtained in space. If such 
point measurements are obtained using some kind of invasive probe (as is done most often), then obtaining the distribution of the local phase volume fraction involves a tedious data collection process. This, in addition to their intrusive nature constitutes a serious drawback in using probes to obtain the local phase holdup in two or three phase flow systems.

\subsection{Global Techniques}

The simplest method of measuring the overall fractional gas holdup in two phase systems is rather straight forward. The knowledge of the volume occupied by the phase of interest as well as the volume of the expanded multiphase dispersion suffices for the needed calculation. For a system with uniform cross-section the process involves the measurement of the height of the dispersion $H_{g}$ at operating conditions and that of the static column (with no gas flow), $H_{0}$, and calculating the gas holdup from :

$$
\epsilon=\left(H_{g}-H_{0}\right) / H_{g}
$$

Frequently an accurate measurement of the height of the dispersion is not possible either due to the fluctuation of the level of the free surface due to bubble disengagement (especially at high gas flow rates) or due to the formation of foam at the free surface of the dispersion. Generally, an average of several observed readings is adopted to minimize the error in the measurement. Although, most often the height of the dispersion is obtained directly, with the aid of a length scale, other methods have also been used. A novel method involving the use of a hot film anemometer has been used by Deckwer et. al. (1980) for determination of the free surface of the dispersion in a slurry bubble column. The hot wire was first calibrated in the gas and the slurry phase. With the top of the column as reference, the hot wire is moved down towards the suspension and, when it touches the slurry phase, the heat removal and, hence, the electric current, increases sharply thereby enabling an accurate measurement of the local height of the dispersion. Clark (1987) has used a neutron based technique for detecting the free surface of the slurry in a high pressure bubble column. The method is based on the ability of the hydrogen dense liquid phase to scatter more neutrons than the gas. The gas liquid interface is detected by moving the assembly of the neutron source and detector down the reactor until a decrease in the neutron flux is detected. The precision of interface detection is reported to be $\pm 5 \mathrm{~mm}$. The method can also be implemented using a $\gamma$ ray source instead of the neutron beam. All these methods, however, still contain an error associated with the fluctuation of the free surface. In addition, the measurement made of the free surface is local and instantaneous. Consequently, a true average can be obtained by making the measurement at different points and at different instants of time. 
For non-transparent columns, as in most industrial situations, the position of a float can be used for detecting the free surface. The position of the float, as it moves with the free surface of the dispersion, is transmitted either through a system of linkages or a string and pulley arrangement to a pointer moving along a length scale. This method has the advantage in that the float dampens out some of the fluctuations of the free surface of the dispersion.

Another method that has been adopted for obtaining the overall fractional phase holdup in two phase systems is to infer it from the measurements of the pressure drop along the height of the column. The theoretical background for the technique has been presented by Hills (1976), as well as by Merchuk and Stein (1981). In gas-liquid systems, if the liquid flow rate is small then, to a good approximation, the pressure drop can be wholly attributed to the hydrostatic head as :

$$
\frac{d P}{d h}=-\rho_{l} g(1-\epsilon)
$$

where $h$ is the axial coordinate pointing upwards and $\rho_{l}$ is the liquid (two phase system) or slurry (three phase system) density. The actual measurement can either be of the static pressure, or of the differential pressure using manometers or some kind of a pressure transducer. If $d z$ represents the height difference observed in a differential manometer, the following expression holds :

$$
\rho_{l} g \frac{d h}{d z}=\frac{d P}{d z}+\rho_{l} g
$$

From these expressions it follows that

$$
\epsilon=\frac{d z}{d h}
$$

If, however, the liquid flow rate is not negligible, one has to account for the wall shear stress and for the effects of acceleration of the liquid due to voidage changes. Eq 2 must be augmented to include terms for these, and the resulting expression for the void fraction is

$$
\epsilon=\frac{d z}{d h}+\frac{U_{l}^{2}}{g} \frac{d}{d z}\left(\frac{1}{1-\epsilon}\right)+\frac{4 \tau_{w}}{\rho_{l} D_{c} g}
$$

where $U_{l}$ is the liquid superficial velocity, $\tau_{w}$ is the wall shear stress and $D_{c}$ is the column diameter. Eq. 4 constitutes an implicit expression for the overall void fraction. In addition its solution requires some method of determining the wall shear stress for a given flow condition. Generally this is done in terms of the friction factor, $f$. For single phase flows $f$ is obtained from the charts as a function of the Reynolds number. The same approach has been adopted 
by Hills with the assumption of a pseudohomogeneous two phase mixture for the dispersion. Merchuk and Stein (1981) use the correlation of Nassos and Bankoff (1967) for the friction factor expressed in terms of the Reynolds number defined for two phase flow.

Fig. 1 illustrates the principle of the differential pressure gradient method. In general, when this technique is adopted the terms corresponding to the friction and the acceleration effects are usually neglected. The lower the gas flow rate, the better this approximation is. One can also use this method to obtain an averaged void fraction in sections of the column by the measurements taken by a series of pressure taps situated along the column height (Prakash and Briens, 1990, Reilly et. al., 1986, Merchuk, 1986, Nicol and Davidson, 1988). The phase fraction obtained is an average over the volume of the dispersion located between

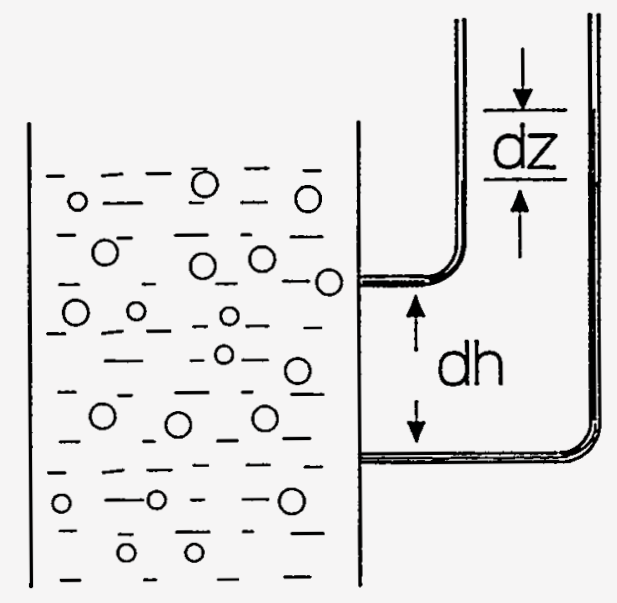

Figure 1: Principle for holdup measurements by means of differential pressure.

the corresponding pressure taps. The method is fairly simple to work with and is applicable to systems at high temperatures and pressures. When one of the phases is a solid, the other being a gas or liquid, then it is necessary to take precautions against clogging of the taps by means of filters or by flushing the taps by a low flow rate of gas. In three phase systems one must also know the solids concentration as a function of height unless the slurry behaves as a pseudohomogeneous mixture.

The overall void fraction can also be measured by what is referred to as the quick closing valves technique (Rosehart et. al., 1975, Colombo et. al., 1967, Yamaguchi and Yamazaki, 1982). It is based on isolating the two phase dispersion between two sections of the test loop and then measuring the mass of the continuous phase. This, along with the known geometrical parameters and the pressure in the system, can be used for estimating the 
holdup between the two sections. The necessary simultaneous closure of two valves that isolate a section of the system is achieved either by coupling the two valves mechanically by springs or by making use of solenoid valves. Although this can be a very accurate method of obtaining a volume averaged gas holdup, it is mainly applicable to small diameter columns. In larger installations the valves may have considerable time constants for closing. Also this method is mainly employed for gas-liquid systems. It can be also be used for gas-solid and liquid-solid systems with moderate solids loading.

Impedance void meters are based on the principle of measuring the electrical impedance of the two phase dispersion. Gas (air) and liquid (water) have significantly different electrical conductivity and permittivity, and this technique exploits this difference. The variation in the flow structure is accompanied by a variation in the impedance of the two phase mixture which is measured by metallic electrodes introduced suitably in the flow. The void fraction is then estimated by adopting a relative impedance technique: The system can be implemented so that the impedance is governed by the conductance or the capacitance or both. It has to be noted that the impedance of the mixture that is sensed by the electrodes depends not only on the void fraction but also on its distribution (flow regime). The void fraction is calculated as a function of the dielectric constants of the two media using theoretical relations. A relation that has found wide acceptance for low void fractions is the one derived by Maxwell (1881) shown here

$$
\frac{\kappa_{m}-\kappa_{w}}{\kappa_{m}+2 \kappa_{w}}=\epsilon \frac{\kappa_{v}-\kappa_{w}}{\kappa_{v}+\kappa_{w}}
$$

where $\kappa$ is the dielectric constant, with subscripts $m, w$ and $v$ signifying the mixture, water and vapor, respectively. Another relation for the slug flow regime is

$$
\epsilon=\frac{1-c / c_{0}}{1-\kappa_{v} / \kappa_{w}}
$$

where $c$ and $c_{0}$ represent the capacitance of the mixture and the liquid, respectively. As noted by Cimorelli and Evangelistic (1967) the reliability of all such relations is poor and direct calibration for each flow regime is necessary. The technique can be adopted to provide an average over a volume whose size can be large or small, and, accordingly, the measurement can be considered as global or local.

For three phase systems no single method can provide both the solids and overall gas holdup. The expansion of solids (when larger solid particles are used) due to the fluidization by either liquid or gas can be measured in a manner similar to the bed expansion method discussed earlier. Three phase fluidized bed reactors are generally of the continuous flow 
type and hence the initial bed height corresponds to the height of the reactor up to which the solids are filled. The bed is then fluidized by either only the liquid phase or a premixed gas-liquid stream. The operating conditions are generally such that the solids are not carried along by the fluids but rather expand to a certain elevation within the column. Once a steady state of operation is established, there exist two distinct regions in the flow referred to as the three phase region and the freeboard region. The height of the three phase region is measured as the expanded bed height. The overall solids holdup in the three phase region is calculated using the expression :

$\epsilon_{s}=$ Vol. of solids loaded / Vol. of three phase dispersion

If measurements from another technique, such as the pressure drop method are available, the individual gas and liquid holdups can also be obtained in conjunction with the solids holdup obtained from the bed expansion. Since, solids holdup in such systems is often a function of the vertical position in the column, this technique only provides the overall gas and liquid holdup in the three phase region. In gas-sparged slurries with small solid particles, the liquid-solid slurry is most often approximated as a pseudohomogeneous liquid. An effective density is obtained, and the methods described for gas-liquid systems can then be used.

Recommendation : For estimation of the overall fractional gas holdup one should measure the pressure profile along the reactor length and provide a rough comparison for it by the bed expansion method. The height of the dispersion in the slurry column can be obtained by a $\gamma$-ray densitometer (such as the one already in use at Laporte). Table 1 provides a comparison of the characteristics of the available methods for overall gas holdup measurement.

\subsection{Line Average Measurements based on Radiation Techniques}

A holdup measurement that can be considered to be in between the overall and point measurement is based on absorption of radiation. Extensive reviews of this technique have been written by Hewitt (1978), Jones and Delhaye (1976), Banerjee and Lahey (1981), and by Snoek (1988). A good introduction of the principles behind some of the techniques has been presented by Schrock (1969).

In most applications it is the attenuation of the radiation (X-rays or gamma-rays) that serves as the basis for the measurement. The absorption of a narrow beam of radiation of initial intensity $I_{\circ}$ by a homogeneous material with a mass attenuation coefficient $\mu$ is expressed as : 
Table 1: Utility of Different Techniques for Overall Gas Holdup Measurement

\begin{tabular}{|c|c|c|c|c|}
\hline & $\begin{array}{c}\text { Bed Expansion } \\
\text { Method }\end{array}$ & $\begin{array}{c}\text { Pressure } \\
\text { Gradient Method }\end{array}$ & $\begin{array}{c}\text { Quick Closing } \\
\text { Valves }\end{array}$ & $\begin{array}{c}\text { Impedance Void } \\
\text { Meters }\end{array}$ \\
\hline Intrusiveness & 1 & 1 & 5 & 3 \\
\hline $\begin{array}{c}\text { Applicability in } \\
\text { Aqueous Systems }\end{array}$ & Yes & Yes & Yes & $\begin{array}{c}\text { No (Capacitive } \\
\text { meters) }\end{array}$ \\
\hline $\begin{array}{c}\text { Applicability in } \\
\text { Hydrocarbon Systems }\end{array}$ & Yes & Yes & Yes & $\begin{array}{c}\text { No (Conductance } \\
\text { meters) }\end{array}$ \\
\hline $\begin{array}{c}\text { Applicability in } \\
\text { 3-Phase systems }\end{array}$ & Yes & Not sufficient & Yes & No \\
\hline Accuracy & $3-4$ & $2-3$ & $1-2^{*}$ & 2 \\
\hline $\begin{array}{c}\text { Ease of Use } \\
\text { \& Adaptability }\end{array}$ & 1 & 2 & 5 & 3 \\
\hline Cost of System & $1-2$ & $2-3$ & 4 & 3 \\
\hline
\end{tabular}

Numbers in table indicate a ranking on a scale of 1 to 5 . Rank 1 indicates that the technique is most suitable and rank 5 signifies that the technique is not to be preferred. Ranking for the cost of the system is based on 1 representing the least expensive and 5 representing the most expensive system.

* provided valves close rapidly and simultaneously 


$$
I=I_{0} \exp (-\rho \mu l)
$$

where $I$ is the intensity of radiation detected after the beam has traveled a distance $l$ through the absorbing medium. For a mixture of two substances, say a gas and a liquid with an attenuation coefficient $\mu_{g}$ and $\mu_{l}$ and densities $\rho_{g}$ and $\rho_{l}$, respectively, the corresponding relation is

$$
I=I_{0} \exp \left[-\left(\rho_{g} \mu_{g} l_{g}+\rho_{l} \mu_{l} l_{l}\right)\right]
$$

where $l_{g}$ and $l_{l}$ are the path lengths of the beam in the gas and the liquid, respectively. In terms of the measured intensities $I_{t p}, I_{f}$ and $I_{m t}$ corresponding to the test section with the two-phase mixture, full of liquid and completely empty, respectively, the chordal average void fraction is computed from:

$$
\epsilon=\frac{\ln \left(I_{t p} / I_{f}\right)}{\ln \left(I_{m t} / I_{f}\right)}
$$

This expression is applicable only in two-phase systems and only when a narrow collimated beam is used in the measurement process. However, many early studies have used what is referred to as the one shot method wherein an uncollimated beam of radiation as wide as the test section of interest is used. Use of Eq. 9 in conjunction with this method is known to result in large errors because of the dependence of the attenuation process on the distribution of the voids i.e., on the flow regimes.

In principle, the void fraction profile can be determined to a fine detail by having a source emitting a narrow beam of radiation and an opposing detector scan across the crosssection. This yields a series of chordal average measurements. To obtain a distribution of the void fraction across a given cross-section, one would have to obtain a series of such scans at different angular orientations. The process of obtaining the voidage profile from such measurement is commonly referred to as tomography. Figure 2 illustrates the differences in the data collection procedures of densitometry and tomography.

For industrial systems it is convenient and less expensive to obtain a few chordal measurements of the attenuation through the test section. Unfortunately, it is often forgotten that a single line averaged holdup, even if it is obtained across the centerline of the column is not representative of the cross sectional mean. The line averaged holdups along several chordal positions can, however, be used to obtain a cross-sectional mean provided that one assumes that the holdup distribution is axisymmetric. If such an assumption can be made, the radial variation of the holdup and hence the cross-sectional mean can be obtained by 


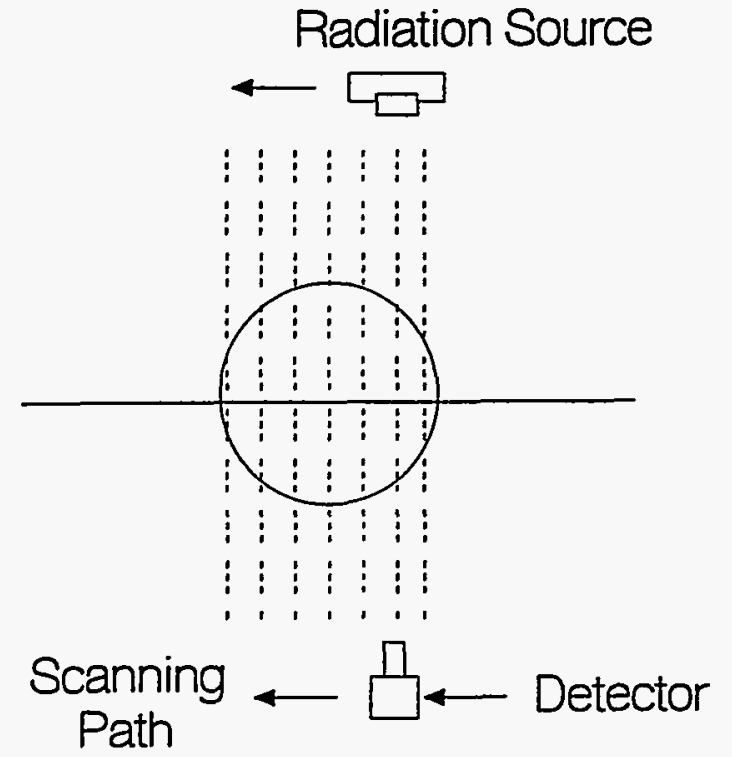

Densitometry

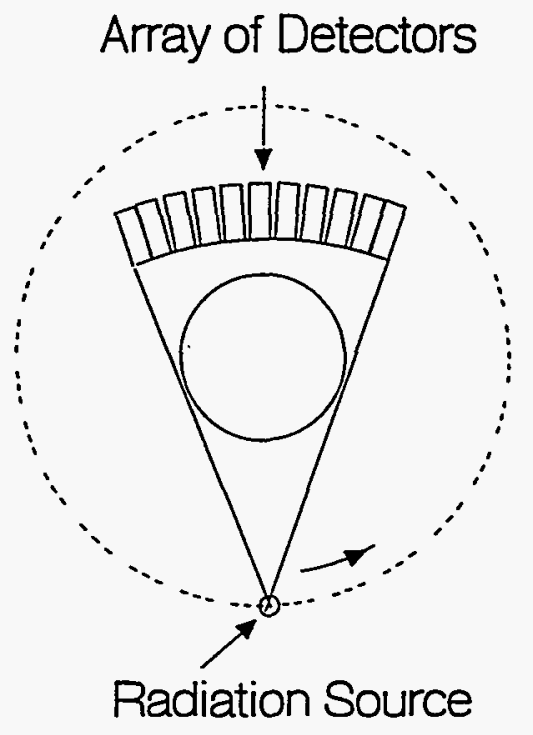

Tomography

Figure 2: Data collection for densitometry and tomography.

making use of the Abel integral and its inversion.

If $f(r, R)$ is a function of radial position that is nonzero only within a circle of radius $R$, then its Abel transform is

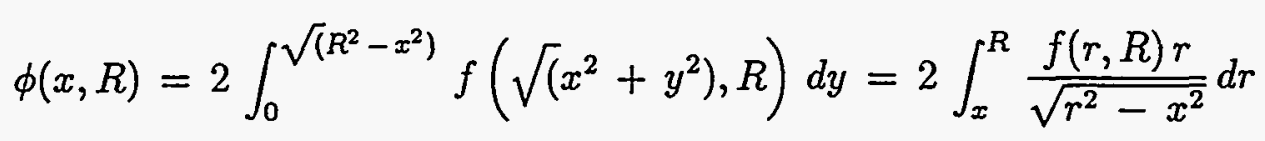

The above is merely the line integral along the ray in the $y$ direction at the position $x$ in the $\mathrm{x}-\mathrm{y}$ coordinate system. The inversion expressing $f$ in terms of $\phi$ is

$$
f(r, R)=-\frac{1}{\pi} \int_{r}^{R} \frac{d \phi / d x}{\sqrt{x^{2}-r^{2}}} d x
$$

For our case, the quantity $\phi(x, R)$ corresponds to the quantity $\ln \left(I_{0} / I\right)$ divided by the corresponding chordal length. Many different numerical approaches have been suggested for the implementation of the Abel inversion (Bockasten, 1961, W. L. Barr, 1962, Dong and Kearney, 1991). To illustrate that the centerline averaged holdup is an overestimate of the cross-sectional mean, and that the Abel inversion provides a radial distribution that leads to 
the correct cross-sectional mean, the following simulation has been made. An axisymmetric distribution of the holdup is assumed in an air-water bubble column of $19.05 \mathrm{~cm}$ in diameter. The assumed radial distribution has the functional form (Kumar, 1994)

$$
\epsilon(\xi)=\bar{\epsilon} \frac{m+2}{m}\left(1-c \xi^{m}\right)
$$

where $\bar{\epsilon}$ is the cross-sectional mean holdup, $m$ is the power law exponent and $c$ is a constant that provides for non-zero holdup at the wall of the column. These parameters were obtained from the experimentally determined void fraction distributions using the CT scanner at CREL (Kumar et al., 1995) a schematic of which is shown in Fig.3. The value

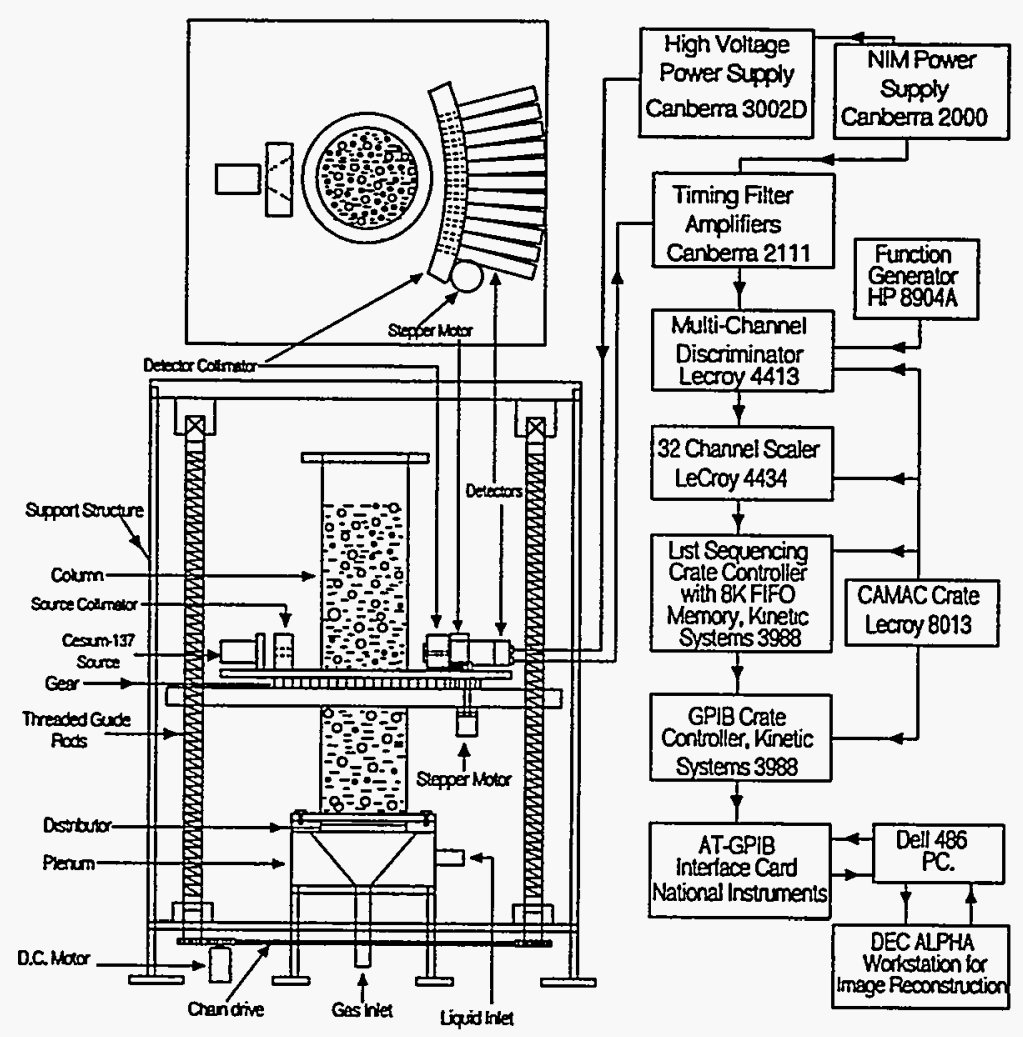

Figure 3: Schematic of the CT scanner at CREL

of the power law exponent is high for a flat holdup distribution (corresponding to bubbly flow) and decreases for the more parabolic profile that is observed in churn turbulent regime. For a given holdup distribution the line integrals corresponding to the quantity $\int\left(\mu_{\text {air }} \epsilon+\mu_{\text {water }}(1-\epsilon)\right) d l$ are computed. The limits of integration depend on the position of the chord. The negative exponential of this quantity would correspond to the ratio 

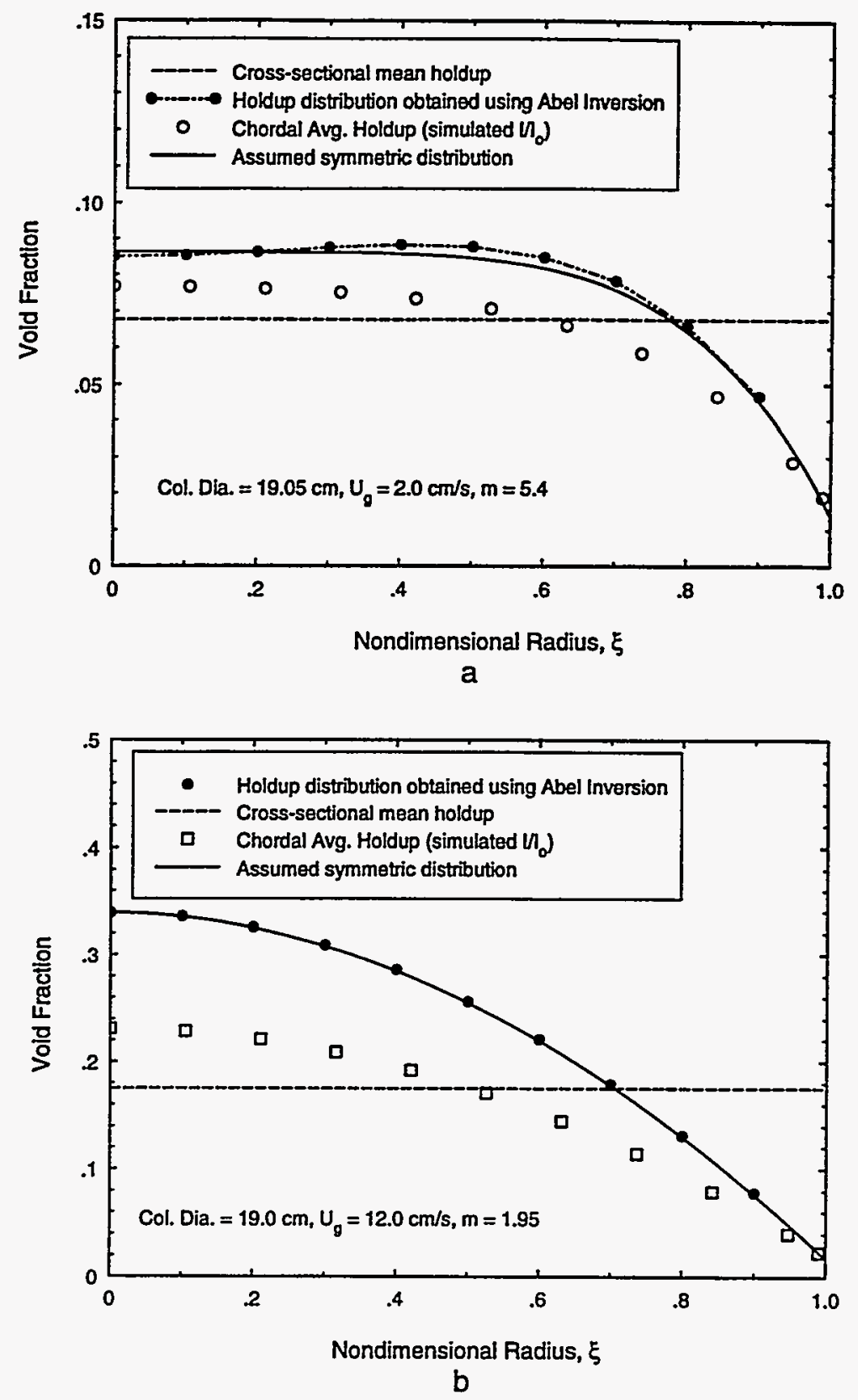

Figure 4: Comparison of assumed distribution, chordal averages and Abel inversion

$I / I_{\circ}$ that is measured in densitometry (as well as CT). Shown in Figures 4 (a) and (b) are the assumed symmetric holdup distributions (similar to experimentally determined holdup profiles in the two flow regimes), and the chordal average holdups that are obtained from the simulated line integrals for two values of $m$ corresponding to bubbly and churn turbulent regimes, respectively. Also shown as a horizontal line for comparison is the cross-sectional mean. The chordal averaged centerline holdup is always higher than the cross-sectional mean. Using the entire set of chordal measurements, the Abel inversion provides a radial distribution that is the same (within numerical error) as the assumed (original) axisymmetric distribution. Abel inversion yields reliable results only when the distribution is axisymmetric. For industrial systems the current measurement practice can be modified to provide 
the chordal average measurements at two positions at right angles to each other. An assessment can than be made whether the assumption of axisymmetry is appropriate and if so a cross-sectional mean using Abel inversion can be obtained.

The important advantage of X-ray or $\gamma$-ray based techniques is that it can be adopted for studying a wide range of systems including high pressure and high temperature systems. The type of radiation that can be used can be X-rays or $\gamma$ rays, $\beta$ rays (applicable only for small test sections) or neutron beams. However, due to their higher penetrating capabilities $\mathrm{X}$-rays and $\gamma$ rays are the preferred types of radiation. The method lends itself to a certain degree of automation and consequently can be used to provide local information to supplement the global information provided by the bed expansion and the pressure drop method.

The use of densitometry or tomography as described above is not sufficient for threephase systems for which the pseudohomogeneous approximation for the mixture of solid and liquid phases cannot be made. This is because in this case there are three unknowns viz., the holdups of the three phases, while the attenuation measurement provides only one equation. This along with the overall mass balance is not sufficient to discriminate between all three phases. If the linear attenuation coefficients for the gas, liquid and solid phases in a three-phase system are denoted by $\mu_{g}, \mu_{l}$ and $\mu_{s}$, respectively, and the corresponding void fractions are denoted as $\epsilon_{g}, \epsilon_{l}$ and $\epsilon_{s}$ respectively, then the transmission ratio for a three phase system can be expressed as :

$$
\ln \frac{I_{0}}{I}=\int\left(\mu_{g} \epsilon_{g}+\mu_{l} \epsilon_{l}+\mu_{s} \epsilon_{s}\right) d l
$$

where overall continuity requires

$$
\epsilon_{g}+\epsilon_{l}+\epsilon_{s}=1
$$

All the three quantities $\epsilon_{g}, \epsilon_{l}, \epsilon_{s}$ cannot be obtained by a conventional single energy CT. If measurements taken at two different photon energy levels are available, it is possible to resolve the holdup of the individual phases. This technique, known as dual energy CT, takes advantage of the functional dependence of the attenuation coefficient of a material on the energy of the photons. The solution of the simultaneous equations resulting from the two transmission measurements described by Eq. 13 and Eq. 14 is best accomplished when the radiation at one energy level is primarily attenuated by one phase, and the radiation at the other energy level is attenuated mainly by the other phase. Consequently, the photon energy of the second source needs to be different from the first one by a significant amount in order to provide a unique second measurement for the accurate distinction of the third 
phase. Otherwise the equations are ill conditioned. In practice such sources can be found (e.g. Cesium - 137 with a photon peak at $660 \mathrm{keV}$, and Americium - 241, with a photon peak at $60 \mathrm{keV}$ ). The attenuation coefficients of some materials at these photon energy levels are tabulated in Table 2. The draw back with the Americium - 241 source is that its photon energy is low requiring a large sampling time for counting with good statistics. Consequently, the time required for a complete scan with Americium - 241 as a second source would amount to more than a day. One can, however, use dual energy methods for densitometry purposes and obtain a few chordal average measurements for the holdup of the three phases.

Table 2: Linear Attenuation Coefficient of some materials as a function of energy

\begin{tabular}{|c|c|c|}
\hline Material & $\mu-c m^{-1}$ at $60 \mathrm{keV}$ & $\mu-c m^{-1}$ at $660 \mathrm{keV}$ \\
\hline Air & $2.14 \mathrm{E}-4$ & $9.29 \mathrm{E}-5$ \\
\hline Water & 0.197 & 0.0857 \\
\hline Glass beads & 0.5625 & 0.184 \\
\hline
\end{tabular}

Another possibility is to use $\mathrm{X}$-rays instead of $\gamma$-rays for the dual beam measurement. The advantage with $\mathrm{X}$-rays is that by changing the voltage of the cathode of an $\mathrm{X}$-ray generator the energy of the emitted radiation can be changed. However, the difference in the energy levels obtainable is not very large and would not be the most ideal setup for dual energy tomography. Dual beam densitometry has been used by Daly and Bukur et al. (1995) for obtaining radial and axial void fraction distribution in a slurry bubble column under Fischer-Tropsch synthesis conditions. The densitometer consisted of a $35 \mathrm{mCi}$ Cobalt$60(1.17,1.33 \mathrm{MeV})$ and a $50 \mathrm{mCi}$ Cesium-137 $(0.661 \mathrm{MeV})$ collimated sources each of which is associated with a NaI detector. The system of sources and detectors are mounted on a movable assembly mechanism, which allows the positioning of the gauges both axially and laterally with respect to the column. This allowed measurements to be made at different axial locations. The two densitometers were separated by an axial distance of $0.25 \mathrm{~m}$. Dual beam tomography has also been accomplished with the combination of $\gamma$-ray and capacitance tomography by Johansen et. al. (1995) at the University of Bergen in Norway. The system is designed for imaging horizontal multiphase flow in a pipe of $82 \mathrm{~mm}$ in diameter. The gamma ray system uses a $500 \mathrm{mCi}$ Americium - 241 source and a set of 85 detectors. The capacitance tomographic system makes use of 8 electrodes each $10 \mathrm{~cm}$ long providing for a total of 28 capacitance measurements. 
Another experimental technique for measuring gas holdup and solids concentration relies on ultrasound. The measurement can be based on either the transmission, or the time of flight of a beam of ultrasound. The principle for the transmission method is identical to that of the radiation absorption described earlier. For a gas-liquid system the attenuation or the absorption coefficient is a function of the bubble size distribution, the projected area of the bubbles, and the wave number of the ultrasonic beam. The constraints that need to be met for using attenuation of ultrasound for holdup measurements in three phase systems are as follows:

1. Particles and bubbles should be of uniform size and belong to a unimodal distribution.

2. Particle sizes should be much larger than the wavelength of the radiation but smaller than the beam diameter and the particles should be approximately spherical.

3. Multiple scattering effects should be negligible. In practice this means that the holdup of the dispersed phase should be small, usually less than $10 \%$. An additional factor limiting the holdup of the dispersed phase is that the governing relations are extended from those corresponding to single particle interaction with the beam and hence the inter particle distances have to be large.

Thus, this technique works well for systems with low void fraction (10 to $15 \%$ ) and for small test sections. For larger test sections one would have to introduce the transmitter and receiver of ultrasound inside the reactor to get the information on a local scale. Stravs and Stockar (1985) have used this method for obtaining holdups in gas-liquid flows with low holdup ( 3 to $4 \%$ ).

For the holdup measurement based on the time of flight of ultrasound the transmittance time through the pure phases and through the two-phase dispersion needs to be determined. The fraction of the voids along the path of the sound wave propagation is computed from :

$$
\epsilon=\frac{t^{*}-t_{1}}{t_{2}-t_{1}}
$$

where $t_{1}, t_{2}$ and $t^{*}$ are the travel times in the pure phases and the dispersion, respectively and $\epsilon$ would be the holdup of phase 2. Tsouris et al. (1990) have used this method for real-time holdup monitoring in control of extraction columns.

Recently Soong et al. (1996) have attempted to measure solids concentration in a three phase reactor using transmitted ultrasonic waves. They developed a probe which shows potential for operating at high temperature $\left(300^{\circ} \mathrm{C}\right)$ and pressure. The specific arrival times of a pulse of ultrasound at a transducer along with the arrival times in a test section with only the fluid is used in the reconstruction process. 
Okamura et. al. (1989) have devised a novel indirect method for measuring solids holdup by analyzing the shape and phase lag or lead of an ultrasonic wave transmitted through a three phase system. The phase lag or lead is only a function of the solids concentration and is unaffected by the presence of bubbles. This provides an average value of the solids holdup along the ultrasound beam path. The requirement, however, is that the temperature of the medium remains constant.

Tomography based on transmission of ultrasound has been used for bubbly flow conditions by Wolf (1988). The argument in favor of the use of ultrasonic techniques as opposed to the ones based on nuclear radiation is safety consideration. However, ultrasonic techniques are not applicable for flows with high gas holdups since then effects of multiple scattering become high, and allowable distance between the transducers cannot be too large.

More recently electrical impedance measurements coupled with tomographic principles have been introduced for void fraction measurements (Dickin et. al. 1993, Xie et. al. 1992). The method is based on measuring the electrical resistance or the dielectric permittivity in the flow between pairs of electrodes, a number of which are evenly spaced around the test section. The hardware for the system is basically similar to the impedance void meters discussed in the section on global measurement techniques. The procedure for measurement involves pulsing an alternating current via one pair of electrodes and measuring the voltage at other pairs of electrodes. The procedure is repeated for all possible combinations of pairs of electrodes. The differences in electrical resistivity (or permittivity) between the phases is used to map the momentary distribution of the phases in the cross-section. Although they have the advantage of being capable of fine time resolution, the measurements made are not just a function of the voidage but also of a number of other parameters such as the electrical properties and temperature of the medium, the flow distribution, etc. All of this limits the spatial resolution compared to X-ray or $\gamma$-ray tomography. Current techniques do not yield resolution better than a centimeter (Xie et. al., 1995). Applicability in flows with high void fractions or high solids concentrations is yet to be demonstrated. In addition, imaging different sections of the flow is quite cumbersome because the electrodes are integrated into the wall of the test section.

Recommendation: The ideal system for obtaining the chordal averaged void fractions in systems as large as the Laporte reactor is a $\gamma$-ray densitometer. The basis for this claim is the higher penetration capabilities of $\gamma$-rays in comparison to say neutron beams or ultrasound. Unfortunately the reactor is essentially operated as a three-phase system, and interpretation of densitometry results is only possible if one can consider the slurry as a pseudo-homogeneous phase and treat the system as a two-phase system. The vertical scanning capabilities of the densitometer can be utilized for obtaining an axial density profile. If 
another radiation source such as Am 241 can be obtained, the axial variation of the solids concentration can also be obtained. These measurements would complement the overall phase holdups-obtained by the global measurement methods recommended earlier.

\subsection{Probes for Local Gas Holdup and Solids Concentration Mea- surement}

One way of measuring the local void fraction is by means of probes. These probes can be based on electrical impedance or optical principles.

\subsubsection{Impedance Probes}

The electrical impedance probes can be further based on either conductive or resistive or capacitive effects. A conductivity probe makes use of the difference in conductivity of the gas and liquid phase and is quite suitable for aqueous gas-liquid systems. Resistivity probes sense the variation in resistance between two electrodes with the passage of bubbles through the gap between them. They are more suitable for measurement of solids concentration. Similarly, a capacitance probe uses the difference in the dielectric constant associated with each phase for phasic discrimination. They can be used in non-polar media and have been used more often for solids concentration measurements in fluidized beds and three phase systems.

A possible choice for the measurement of gas holdup in a three phase reactor would be a conductivity probe. The electrical conductivity probe essentially consists of a stainless steel insulated needle exposed only at the tip and a larger electrode mounted on the wall. With the liquid in contact with the probe tip the electrical circuit between the needle and the wall electrode is closed and if the tip is immersed in a bubble the circuit gets broken. The electrical operating schematic is shown in Fig. 5. The probe therefore acts like a switch and the signal therefore is binary. The typical output signal from the probe (including the capacitance and optical probes, to be discussed later) is shown in Fig. 6. In practice there is a delay in response to a bubble due to the dewetting time required. The response time depends on how fast the liquid film is sheared off from the probe allowing the signal to rise from the voltage corresponding to the gas phase to that of the liquid phase and vice-versa. Consequently, the signal is not exactly binary with the rise and fall times depending on the tip geometry, bubble size and rise velocity as well as on the surface tension of the liquid. Minimization of the rise and fall time is possible with proper probe design and appropriate signal processing. The void fraction is obtained from the ratio of the integral of the time 


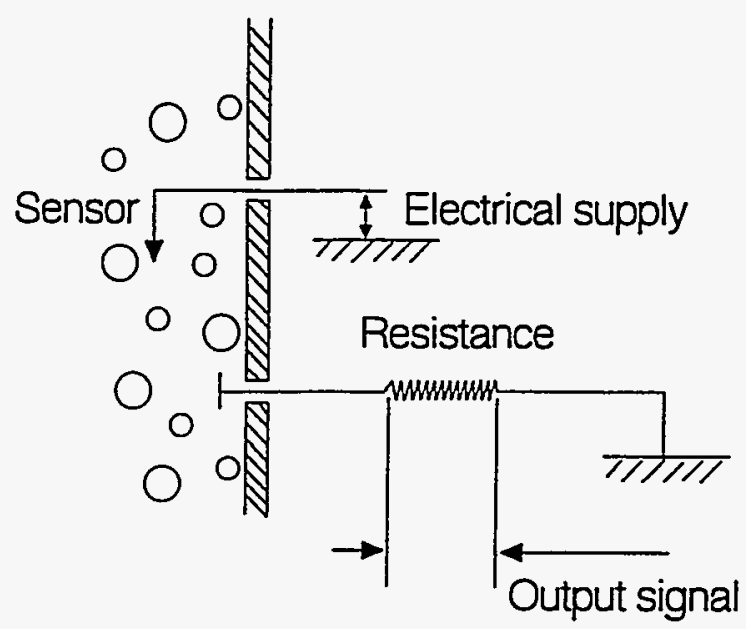

Figure 5: Operating schematic of the conductivity probe.

the probe spends in the gas phase and the total time. Two such needle probes have been integrated together such that their tips are vertically aligned and a small distance apart so that from the measurement of the time of flight of a bubble between the two tips the bubble rise velocity can be estimated (Ueyama et al., 1980; Yasunishi et al., 1986; Matsura and Fan 1984, Ikeda et al., 1986). In general, the measurements from such a conductivity probe are also sensitive to the temperature of the medium, the orientation of the probe with respect to the flow, the flow velocity and changes in the ionic strength (conductivity) of the medium. Thus, one needs either to ensure that the temperature and the conductivity in the flow media are constant or to monitor them constantly and account for the changes. The sensitivity to the direction of the flow is probably of critical importance in situations where the flow velocity in the direction normal to the probe axis is not small in comparison to the velocity along the probe axis, as in stirred tanks. For a bubble column this effect may not be so critical. One would, however, have to orient the probe in the reverse direction for measurement in the downflow region. The effect of the orientation of the probe with respect to the flow direction has been clearly demonstrated by Groen et al. (1995).

For the measurement of the solids concentration in a slurry system a modified form of the conductivity probe can be used (Nasr-El-Din et al., 1987). Their probe consists of two sensor electrodes which are completely insulated from each other and are surrounded by two field electrodes. When the probe is immersed in a conducting fluid such as water, the application of a potential across the field electrodes results in the flow of a small current between the field electrodes. The magnitude of this current depends on the total resistivity of the surrounding medium. With increasing solids concentration the resistivity increases and the current decreases. Relating this change in current provides a measure of the solids concentration. However, the current depends on both the slurry resistivity and the polarization resistance developed on the surfaces of the field electrodes, and the latter is a function 


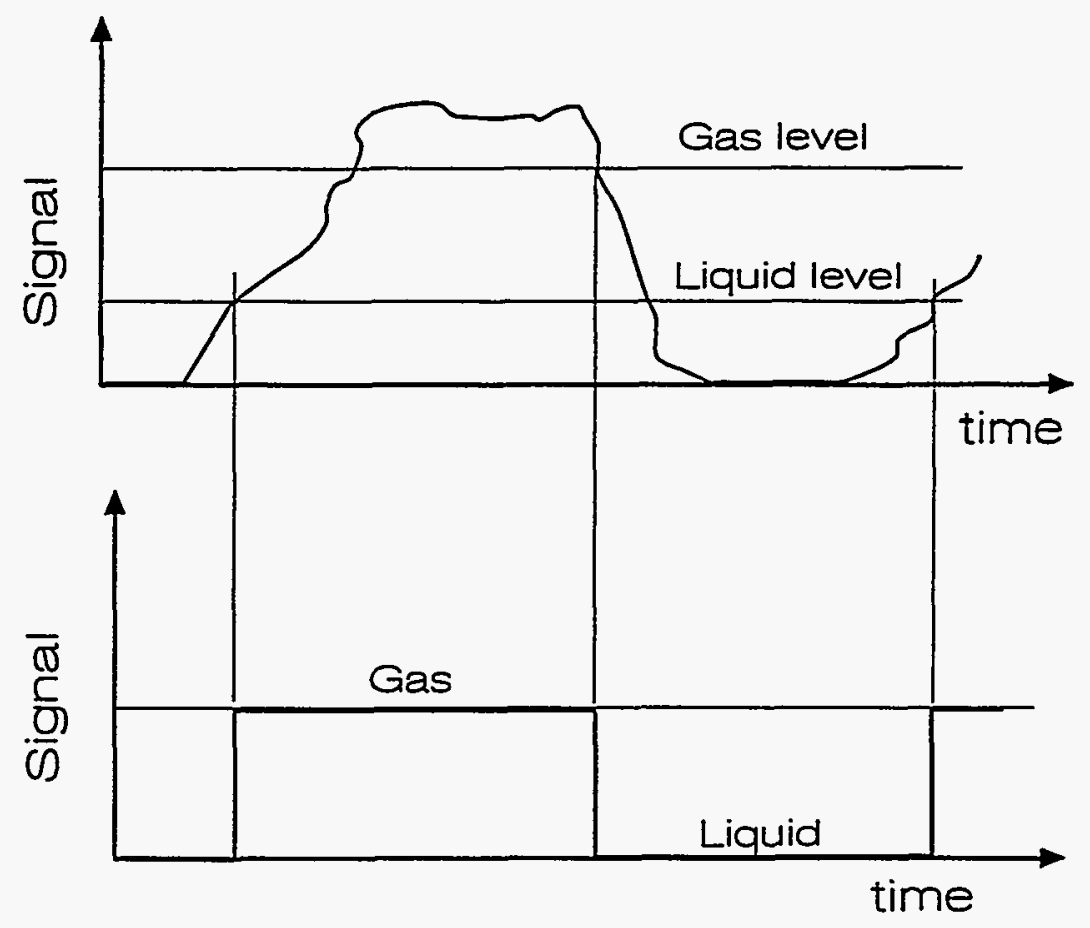

Figure 6: Output signal from a probe.

of velocity. Measuring the voltage across the sensor electrodes removes the effects of polarization. This is because the sensor electrode circuitry has a very large impedance and hence no current flows through them. Thus, the effects of flow velocity on the solids concentration measurement is circumvented. The conductivity probe has been used for solids up to $1 \mathrm{~mm}$ in diameter (or characteristic size) and solids concentrations up to 25 to $30 \%$. An important advantage of this probe appears to be that for non-conducting solids, the solids concentration can be obtained directly from the sensor voltage using the Maxwell equation (5) for mixture conductivity. This eliminates any need for calibration.

Another means of measuring the local solids concentration is a capacitance probe (Riley and Louge, 1989), which senses the variation of the effective dielectric permittivity of the suspension between the two electrodes. The magnitude of the variation in the capacitance due to the variation in solids concentration is of the order of picofarads. This small capacitance is overwhelmed by the cable capacitance and any stray capacitances. The design of Louge and Opie (1990) overcomes this problem by the use of a guard circuit that eliminates all stray capacitances and measures only that between the sensing electrode and the ground. The schematic of their design is shown in Fig. 7. The most important advantage of this system is that one can adapt it to work in high temperature environments. Like the conductivity probe the capacitance probe is also sensitive to its orientation with respect to the flow. 


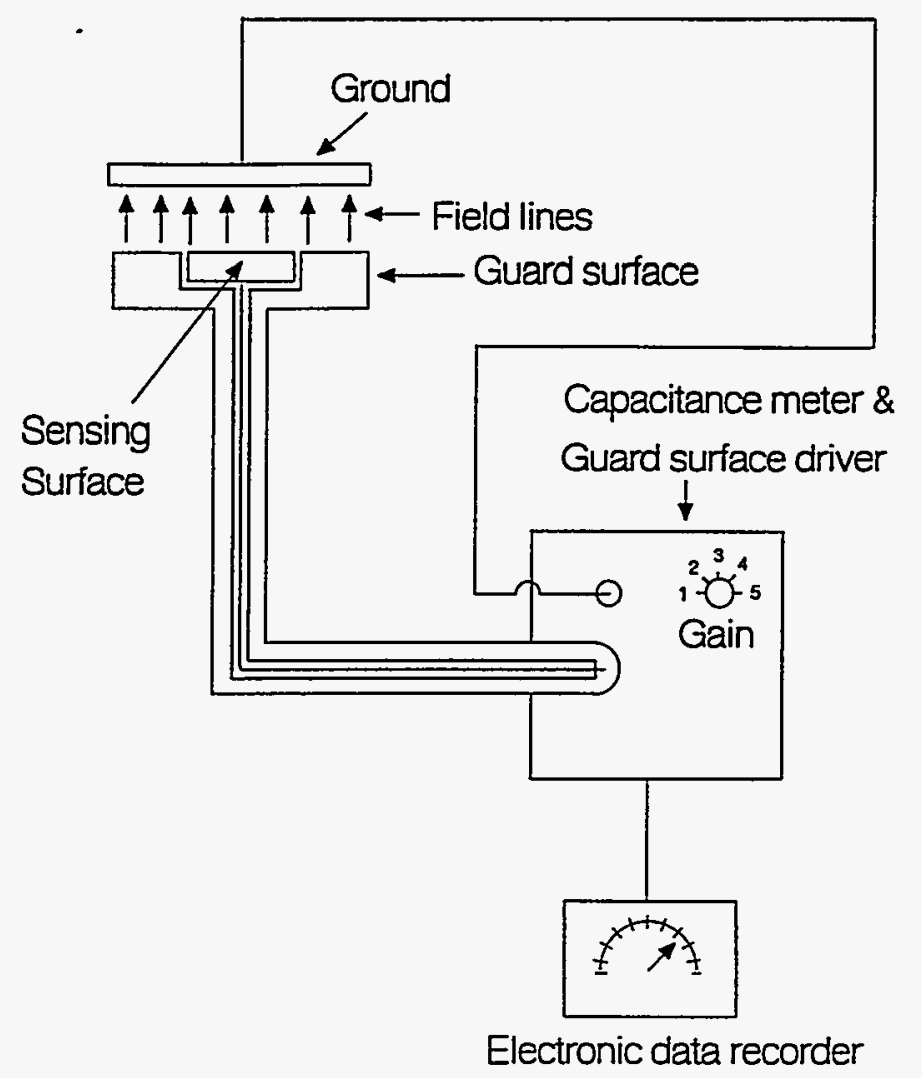

Figure 7: Schematic of the capacitance probe of Louge and Opie.

All the above probes in general can also be used in three phase systems. If the size of the solids is small (of the order of microns), the slurry can be considered as a pseudo homogeneous phase. The signal from a conductivity probe will be binary with the two levels corresponding to the gas and the slurry phase respectively. If the diameter (or the characteristic length) of the solids is quite large, again the signal from the probe is binary (the impact of a solid particle on the probe tip has no significant influence on the signal).

\subsubsection{Optical Probes}

Optical probes exploit the differences in the index of refraction of the two phases and rely on the application of Snell's law at the probe-fluid interface. Depending on which phase exists at the probe's tip the light from the tip is reflected or refracted. The most common optical probe consists of two optical fibers fused and ground to a $45^{\circ}$ angle with respect to the probe axis. The other ends of the fibers are free with one of them serving as an emitter and the other as a receiver. Light detection can be achieved with a phototransistor. In a 
novel approach, De Lasa et. al. (1984). have the optic fiber bent into an U-shape such that the radius of curvature of the $U$ is large enough for the angle of incidence at the turning point to be larger than the angle of total reflection when the fiber is exposed to air (gas). At the same time the radius is to be small enough to secure an angle of incidence at the turning point smaller than the angle of total reflection when the tip is in water (liquid). With this, the light will be conserved in gas and lost in liquid resulting in a significant difference in the detected signals corresponding to gas and liquid. This principle is illustrated in Fig. 8.
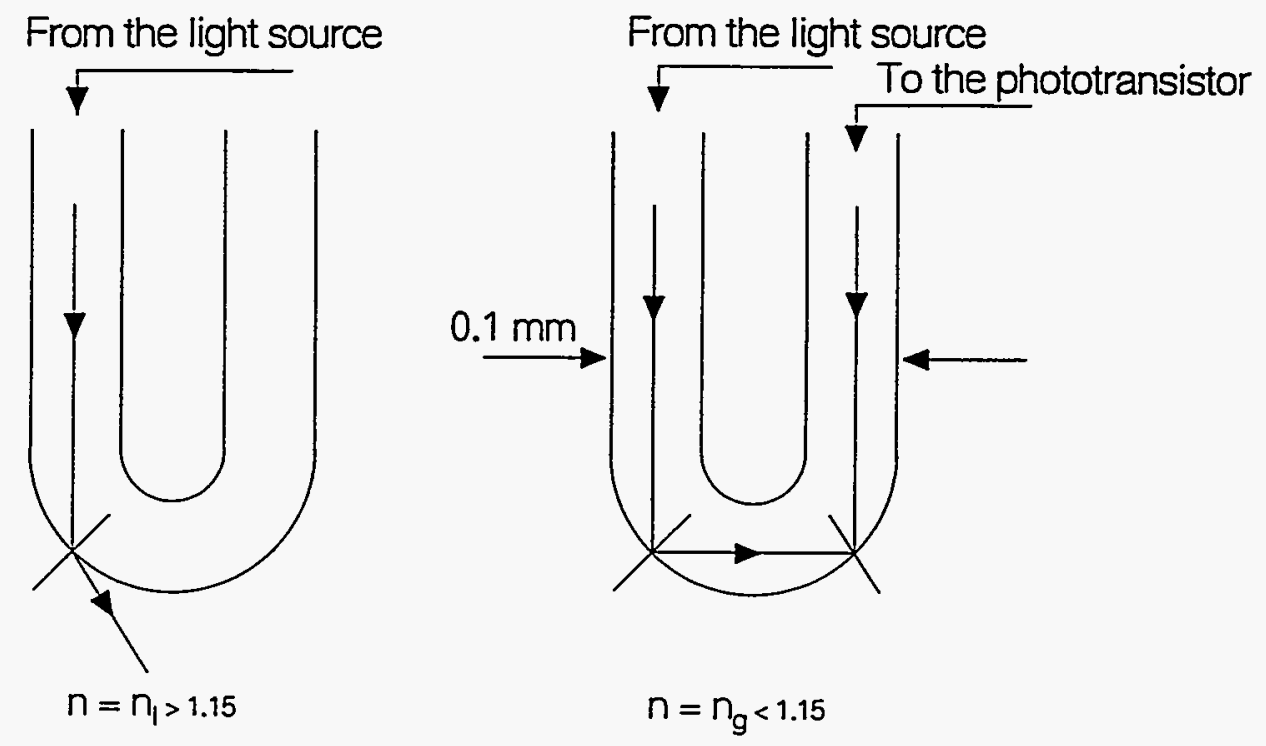

Figure 8: Principle of operation of the optical probe

Optical probes for void fraction measurements have been made by Lance and Bataille (1991), Abuaf et. al. (1979), Moujaes and Dougall (1987). In general, an optical probe can be used only in transparent systems, at low void fractions and at moderate temperatures. The success of the probe in discriminating between the phases depends on good contact between the probe tip and the bubble. Thus, if the bubble size is very small the probe would be unable to detect the changes in voids. The use of the optical probe in a three phase system is considered problematic by Euzen et. al. (1993) mainly because of the difficulties in differentiating between the signals from the solids and the bubbles.

\subsubsection{Other Probes}

The electrochemical probe originally developed by Mitchell and Hanratty (1966), primarily for measuring the wall shear stress has been adopted by Nakaryakov et. al. (1984) for the measurement of liquid velocity and the void fraction in two phase flows. The probe consists 
of a small cathode and a larger anode, with the latter mounted flush with the wall. The flowing liquid has to be an electrolyte of special composition. With the application of a voltage between the electrodes a chemical reaction leads to polarization of the cathode with the concentration of active ions on it going to zero. As a result active ions from the bulk diffuse to the cathode setting up the flow of an electric current in the circuit. The anode, being much larger, does not influence the process, and the current is entirely governed by the diffusion of the active ions to the cathode. If this condition, known as the regime of limiting diffusion current, is satisfied, the current in the electrode will depend on the liquid velocity near the electrode. A solution of the diffusion equation along with a known profile for the velocity is used to relate the current to the velocity. Since the probe is alternatively exposed to the gas and liquid phase, the signal is correspondingly at two different levels so that the void fraction can be estimated from the residence time of the probe in the gas phase.

In addition to the impedance and optical probes, attempts have been made to utilize hot wire or film anemometry (Delhaye, 1969), and even a micro thermocouple (Delhaye and Semeria, 1973), for phasic discrimination and in turn for void fraction measurements. However, as noted by Delhaye (1969), the applicability of anemometery is limited to low flow rates and by the dimensions of the bubble.

As discussed for impedance probes these probes act essentially like a switch depending upon the medium surrounding the probe tip. The ideal signal from the probes should therefore be binary. In practice there is a delay in the response to a bubble due to the dewetting time required. The response time is related to how fast the liquid film is sheared off from the probe allowing the signal to rise from the voltage corresponding to the gas phase to that of the liquid phase and vice-versa. Consequently the signal is not exactly binary with the rise and fall times depending on the tip geometry, bubble size and rise velocity as well as surface tension effects of the liquid. Minimization of the rise and fall time is possible with proper probe design and appropriate signal processing. The void fraction is obtained from the ratio of the integral of the time the probe spends in the gas phase and the total time.

Recommendation: The choice of probe to be used depends to some extent on the physical properties of the liquid phase in the reactor. For liquids such as alcohols, the conductivity probe is more suitable since these liquids are polar in nature and, as such, use of capacitive probes is problematic. On the other hand if the liquid phase consists of paraffins and olefins the conductivity is much lower and these liquids are not as polar as alcohols. Consequently, a capacitance probe would be a better choice. Also, the liquids should have as low a viscosity as possible so that the dewetting time of the probe is small. For the Fischer-Tropsch wax at $250^{\circ}$ this should not be a cause of problems. If only the local gas holdup is of interest, either the conductivity or the resistivity probe (depending on the liquid properties) is the best choice. 
If, however, the solids concentration is also desired, then either the multi-sensor resistivity probe or the capacitance probe can be used. However, despite all the claims that have been made about the capabilities of these latter probes, one would still need to test the probes in simulated conditions to determine their appropriateness for the specific application. Table 3 provides a comparison of the characteristics of the available methods for local void fraction measurement.

\section{Measurement of Bubble Sizes and Velocity}

Unlike techniques for measurement of the local void fraction, the techniques that are available for measurement of bubble sizes and velocity are few in number. The simplest method that can be used for measurement of bubble sizes and their velocity is the photographic method. Pictures of the dispersion are taken through plane parallel windows installed in the bubble column. Using computerized image analysis the bubble sizes as well as their velocities can be estimated. The technique is limited in that the measured bubble sizes are not representative of the true bubble size distribution since the large bubbles rise in the center of the column and most often the image acquired is of the bubbles in the flow closer to the wall. In addition, the system needs to be transparent, and it is also necessary to provide special plane parallel windows at the column wall. This is not a technique that can be used easily on an industrial scale reactor.

The other commonly used method for bubble size measurement is a two point resistivity probe. Such a probe consists of two needles which are fixed at a small vertical distance apart. Each of the sensors has a binary output signal depending on which of the phases is in contact with the tip. As a bubble passes over each of the tips there is a mutual time delay $t_{\text {dly }}$ between the signals from the two sensors due to the time needed for the bubble to proceed from one probe to the other (ref. Fig. 9). The distance $d$ between the probe tips being known, the component of the bubble velocity along the direction defined by the line joining the probe tips can be estimated as :

$$
v_{x}=d / t_{d l y}
$$

This velocity along with the knowledge of the mean residence time of the bubble at one of the probe tips $t_{m}$ can be used to estimate the pierced chord length of the bubble as :

$$
l_{g}=v_{x} t_{m}
$$




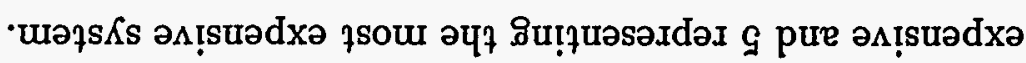

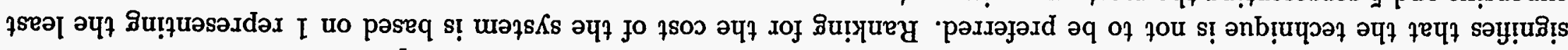

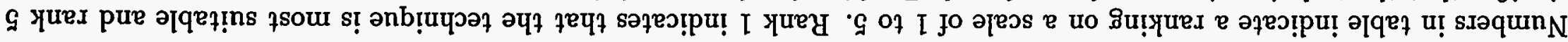

\begin{tabular}{|c|c|c|c|c|c|}
\hline 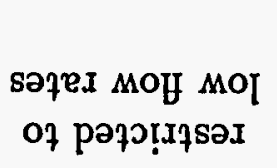 & 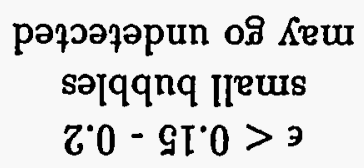 & 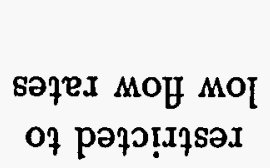 & $\begin{array}{l}\text { safex MOH MOI } \\
\text { of pә7э!xpsax }\end{array}$ & 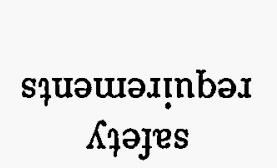 & (s)uo!̣? q!u!̣ \\
\hline$Z$ & $\varepsilon$ & $\zeta$ & $\zeta$ & $\overline{7}$ & шə7s $\kappa_{S}$ fo 7 soD \\
\hline$\varepsilon$ & $\varepsilon$ & $\varepsilon$ & $\varepsilon$ & I & 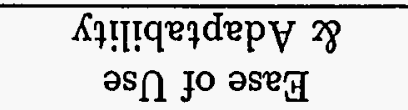 \\
\hline $\bar{T}$ & $\varepsilon$ & $\varepsilon$ & $\varepsilon$ & $\left(90^{\circ} 0<\exists 78\right) I$ & Кวе.mวo \\
\hline$g$ & g & 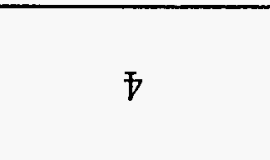 & $\Phi$ & $I$ & 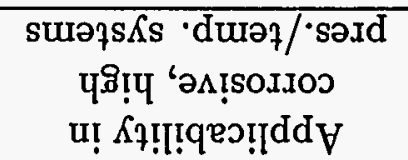 \\
\hline $\mathrm{ON}^{\mathrm{N}}$ & $\mathrm{oN}^{\mathrm{N}}$ & (sp!os) sə $\mathrm{X}$ & (seD) sa $X$ & quə!วษns $70 \mathrm{~N}$ & 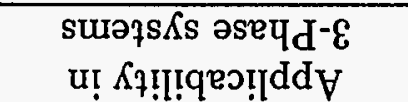 \\
\hline $\operatorname{so} \lambda$ & $\operatorname{sa} X$ & $\operatorname{sə} \lambda$ & $\mathrm{oN}_{\mathrm{N}}$ & so $X$ & 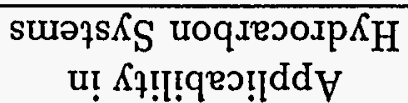 \\
\hline sa $\mathrm{X}$ & $\operatorname{so}_{X}$ & $\mathrm{O}_{\mathrm{N}}$ & $\operatorname{so} \lambda$ & $\operatorname{sa} \alpha$ & 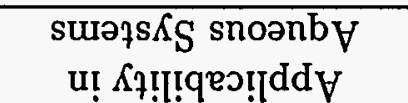 \\
\hline$\overline{7}$ & $\overline{7}$ & 7 & 7 & $I$ & ssəuəs!snxquI \\
\hline 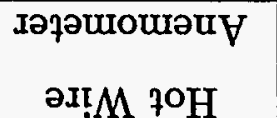 & $\begin{array}{l}\text { əqoId } \\
\text { [eว!qdo }\end{array}$ & $\begin{array}{c}\text { əqoId } \\
\text { əoueqIวedep }\end{array}$ & 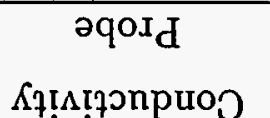 & $\begin{array}{l}\text { spoчqәN } \\
\text { uorqerрey }\end{array}$ & \\
\hline
\end{tabular}

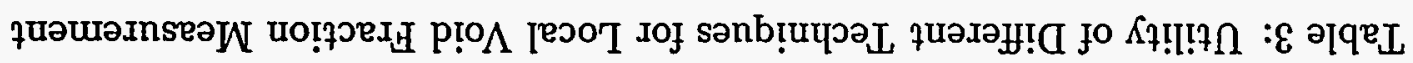




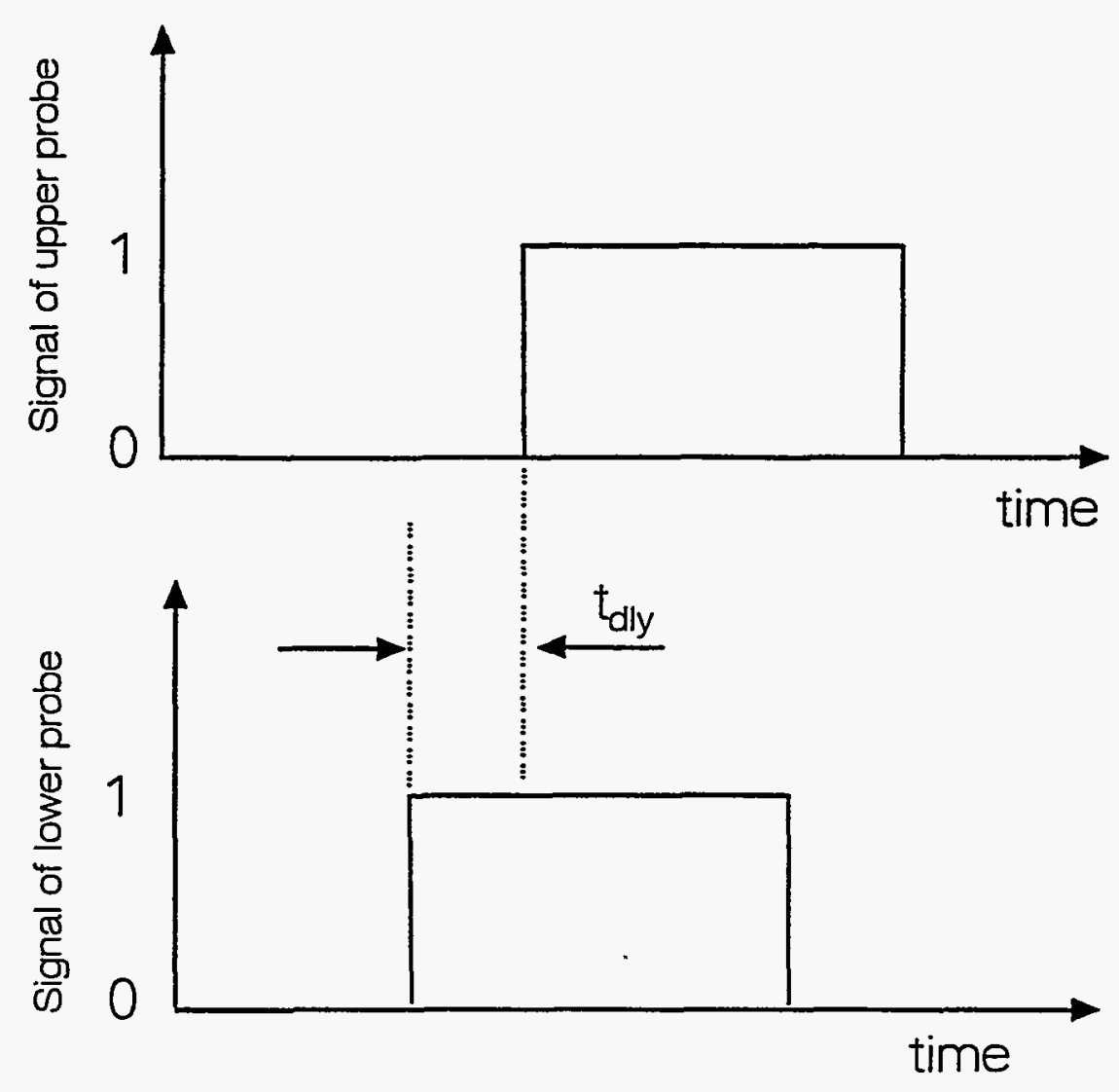

Figure 9: The signals from a two point bubble probe

With this method there are variations in bubble frequency and the corresponding chord lengths obtained using the measurements from the upper and lower sensor. If such variations are statistically significant, this is indicative that there are problems of cross-talk and capacitive effects. This implies that the sensors are too closely spaced together. The optimum separation between the sensors is unfortunately a function of the bubble frequency, the range of bubble chord lengths intercepted by the sensors as well as the sensors size and geometry. Cheremisinoff (1986) recommends that the distance between the sensors should be set at a distance equal to the maximum anticipated bubble size.

There are many potential problems in applying this method to operating slurry bubble column reactors. Bubbles that are rising in a direction not aligned with the two probes lead to major errors, since then it is possible that there is no delay in the signal from the two sensors. This seriously limits their usage in turbulent flow fields. To overcome this difficulty some researchers (Burgess and Calderbank, 1975) have developed multi-point probes. However, these probes can be utilized only in flows where the bubble size is at least $6 \mathrm{~mm}$ (Buchholz et. al. 1981). The velocity of rise, as calculated above by Eq. 16, is applicable only if the bubble is centrally pierced. Steinemann and Buchholz (1984) provide an alternative procedure for 
calculating the rise velocity of bubbles that are not centrally pierced. This is based on assuming a probability density function for the bubble chord distribution, the parameters for which are fitted to the measured chord distribution. If the bubbles are small (less than a $1 \mathrm{~mm}$ ), there is the possibility that a bubble never gets pierced but goes around the sensing probe tips. In order to eliminate the effects of cross-talk between two closely positioned sensors an alternative method of acquiring the mean time delay between the signals from the two tips is to obtain it from the cross-correlation function of both the signals (Zun and Saje, 1982). The two point probe, therefore, is an acceptable instrument for measuring bubble characteristics only if the bubbles are spherical, not too small and have a unimodal distribution.

For the two point optical probe the principle of detecting the bubble sizes and the velocities is identical to that of the two point resistivity probe described above. The limitations described for the void fraction probes based on the same principles apply in this case as well. Chabot (1993) has used the optical probe to study the bubble characteristics in a high temperature bubble column with some hydrocarbons as the liquid phase.

An interesting alternative to the intrusive kind of probes of the kind discussed above is the Ultrasound Doppler Technique (Hilgert and Hofmann, 1986; Lubbert et al., 1987; Broring et al. 1991). Since bubbles are good reflectors of ultrasound, some of the energy of a beam of ultrasound transmitted through the flow dispersion gets reflected into a detector. The measurement principle is illustrated in Fig. 10. Most often the transmitter itself can also serve as a detector. In accordance with the Doppler effect the pulse of ultrasound reflected from the surface of a moving bubble is shifted in frequency by an amount proportional to the bubble velocity. A spectral analysis of the Doppler shift provides a distribution of the bubble velocity components in a direction that bisects the incident and reflected beam. The measuring volume is typically a few centimeters away from the transmitter and, therefore, to obtain the spatial distribution of the measurements the device has to be moved around in the reactor like any other probe. The advantage of the system is that there is no direct interaction between the measuring device and the bubble, although there is some flow disturbance caused by the presence of the transmitter/receiver inside the reactor. It also appears that the technique is applicable only for flows with low holdups (less than $20 \%)$. A higher concentration of bubbles draws the measuring volume closer to the device, and if one persists with longer transmission time to increase that distance, then the error in measurement increases since the effects of transmission of ultrasound become significant. This then leads to errors in the measurement. In addition, one needs to obtain the bubble velocities in at least three directions at each measuring point. A further limitation of the technique is that the ultrasonic transducer cannot operate in environments with temperatures 


\section{Transmitter · Receiver}

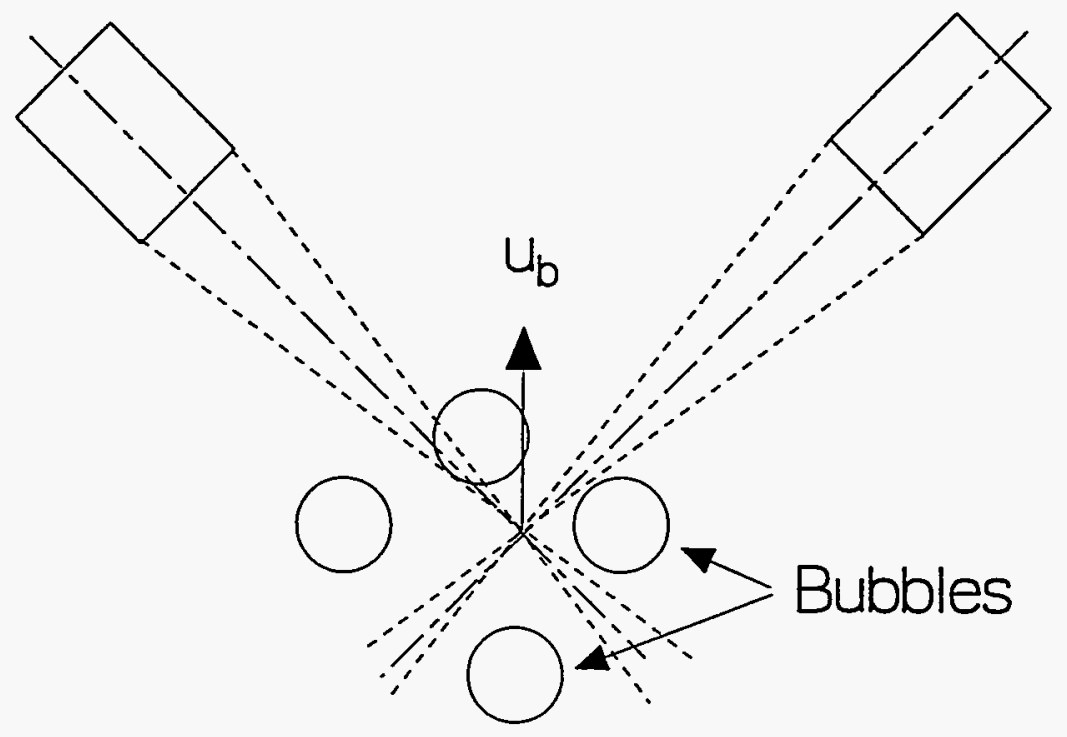

Figure 10: Measurement principle of the Ultrasound Doppler technique

higher than about $150^{\circ} \mathrm{C}$. It also has to be noted that the technique only provides bubble velocities and no information on their sizes.

A technique that provides information only on the bubble sizes is the isokinetic sampling probe. This measurement principle is conceptually different and relies on physically sucking out a sample of the dispersion into a capillary tube. The sampling end of the capillary is funnel shaped with an expansion such that it provides a uniform acceleration as the bubbles get converted into a slug filling the capillary cross-section. A narrow collimated beam of light from an optical switch is directed through the glass wall of the capillary tube. The measured signal consists of the variation in intensity of the transmitted light due to the passage of gas or liquid slugs. These signals are similar to the signals of the conductivity or the optical probes (binary). The time elapsed between the detection of the two ends of a bubble is inferred from this signal. This, along with the known cross-sectional area of the capillary, can be used to estimate the bubble volume. With the assumption of a spherical bubble a diameter for the bubble can be computed. The schematic of the system is illustrated in Fig. 11. Greaves and Kobbacy (1984) and Pilhofer et. al.(1974) have used this method for bubble size estimation.

The principle of isokinetic sampling can also be used for the measurement of solids 


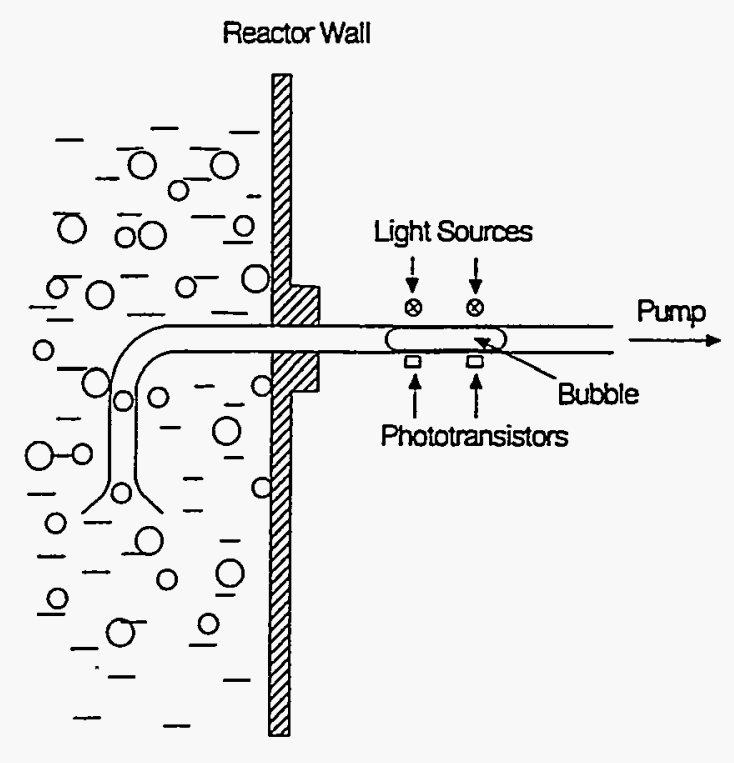

Figure 11: The isokinetic sampling probe

concentration. The key requirement is that the velocity of sample withdrawal and the process stream needs to be matched to prevent sample size differentiation. Since, the velocity of the flow is often not known complying with this requirement is not easy.

A rather simple method that has found wide acceptance for measurement of bubble velocities, and in turn their sizes, is the dynamic gas disengagement technique. The method requires an accurate recording of the rate at which the surface of the dispersion drops once the gas flow is interrupted. The measured disengagement profile is used to estimate the holdup structure that existed just before gas shut off. In its simplest form the technique assumes one or two dominant bubble sizes. The initial part of the disengagement profile is considered to be dictated solely by large bubbles. The small bubbles disengage only after all of the large bubbles have left the system. The disengagement profile (the height of the two phase dispersion as a function of time) has two distinct regions, corresponding to the two bubble sizes, which are fitted with straight lines. A typical disengagement profile for a bimodal distribution is shown in Fig. 12. The slope and intercepts of the straight lines are related to the holdup and the rise velocities of the corresponding bubble sizes. If some relation (correlation) can be assumed between bubble rise velocities and their sizes then, the latter can also be estimated. Assuming that there is no interaction between the two bubble classes the average holdup and the holdup corresponding to the large (transported holdup) and small bubbles (entrained holdup) are estimated from : 


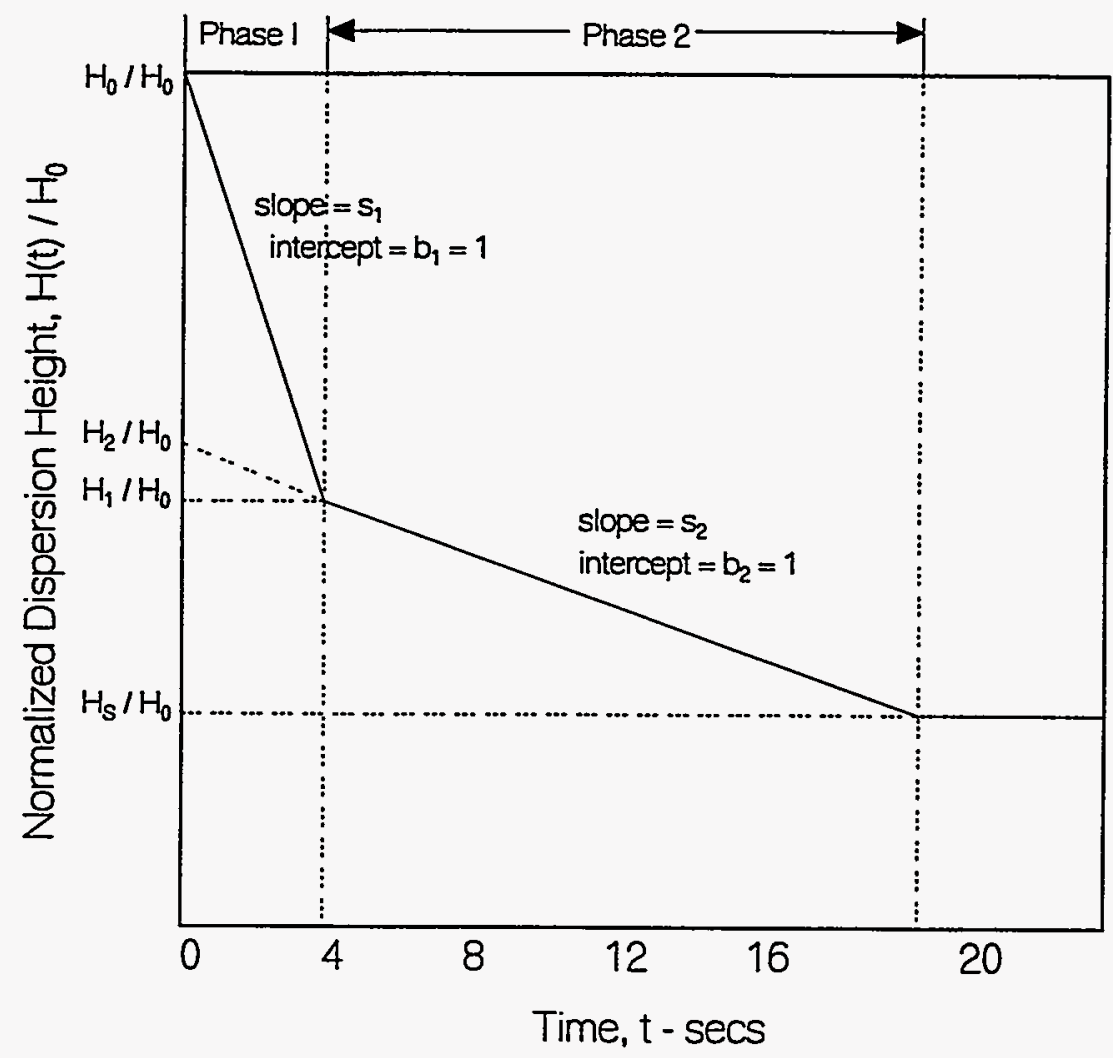

Figure 12: Typical disengagement profile for a bimodal distribution

Average gas holdup :

$$
\epsilon_{\text {avg }}=1-\frac{H_{s}}{H_{\circ}}
$$

Small Bubble Holdup :

$$
\epsilon_{s}=1-\frac{H_{s}}{H_{\circ} b_{2}}
$$

Large Bubble Holdup :

$$
\epsilon_{l}=\frac{H_{s}}{H_{0}} \frac{1-b_{2}}{b_{2}}
$$

where $H_{\mathrm{o}}$ is the steady state dispersion height prior to gas shut off and the quantities $H_{s}$ and $b_{2}$ are defined in Fig. 12. If one takes into account the interaction between the different classes of bubbles as they disengage, the above expressions for the holdup get modified (Patel et. al. 1989).

Most often in the use of the dynamic gas disengagement method it is assumed that there is no interaction between bubbles during gas disengagement and that the dispersion 
is axially homogeneous prior to gas flow interruption. Inspite of its simplicity the dynamic disengagement method provides very useful global information. Vermeer and Krishna (1981), Schumpe and Grund (1986), Patel et. al. (1989) are some of the researchers who have enhanced the utility of the method after Sriram and Mann (1977) introduced it. Sasaki et. al (1986) have extended the technique to multi-modal bubble size distributions.

Recommendation: It has to be accepted that presently there are no techniques available for measurement of bubble characteristics in a reactor operating in the churn turbulent regime at high temperatures and pressure. The two point conductivity probe is not applicable under turbulent flow conditions. Although a multi-point probe can be used in a turbulent, two phase flow field, the bubble sizes need to be large. In a Fischer-Tropsch system the bubble sizes are expected to be small. Optical probes are not suitable either when the bubble sizes are small. Pulsed Ultrasound Doppler technique cannot be used at high voidages as well as at temperatures higher than about $150^{\circ} \mathrm{C}$. The only method that can be adopted with ease for the Laporte reactor appears to be the dynamic gas disengagement technique. Since the reactor walls are opaque recording the drop rate of the free surface of the dispersion can be recorded using pressure taps provided along the reactor height or an automated movable $\gamma$-ray densitometer can be used. Table 4 provides a comparison of the characteristics of the available methods for bubble size and velocity measurement.

\section{Measurement of Liquid and Solid Velocities}

Techniques that have been commonly used for the measurement of liquid velocities in multiphase systems are essentially the ones used in single phase flow with some modifications in the interpretation of the measured data. These methods include the simple pitot tube, devices based on the turbine flowmeter, hot wire or film anemometry, and Laser Doppler Velocimetry (LDV), Particle Image Velocimetry (PIV), Laser Induced Photochemical Anemometry (LIPA), particle tracking and tracer techniques.

The principle of the pitot tube is very well known and is based on measuring the differences in the pressure at the point of interest and the static pressure at the wall. The tube is inserted close to the point of interest in the flow such that its opening faces the flow. The velocity at the point is calculated based on the dynamic pressure measurement. The relationship is

$$
\Delta P=\frac{1}{2} \rho v^{2}
$$

and is applicable for single phase flow. For two phase flow situations the above relation is 
Table 4: Utility of Different Techniques for Bubble Size and Velocity Measurement

\begin{tabular}{|c|c|c|c|c|}
\hline & $\begin{array}{c}\text { Dual Resistivity } \\
\text { Probe } \\
\end{array}$ & $\begin{array}{l}\text { Optical } \\
\text { Probe }\end{array}$ & $\begin{array}{c}\text { Ultrasound } \\
\text { Doppler Method }\end{array}$ & $\begin{array}{c}\text { Dynamic Gas Disen- } \\
\text { gagement Method }\end{array}$ \\
\hline Intrusiveness & 4 & 4 & 5 & 1 \\
\hline $\begin{array}{l}\text { Applicability in } \\
\text { Aqueous Systems }\end{array}$ & Yes & Yes & Yes & Yes \\
\hline $\begin{array}{c}\text { Applicability in } \\
\text { Hydrocarbon Systems }\end{array}$ & No & Yes & Yes & Yes \\
\hline $\begin{array}{l}\text { Applicability in } \\
\text { 3-Phase systems }\end{array}$ & Yes & No & Yes & Yes \\
\hline $\begin{array}{c}\text { Applicability in } \\
\text { corrosive, high } \\
\text { pres./temp. systems }\end{array}$ & 4 & 5 & 3 & 1 \\
\hline Accuracy & 3 & 3 & 2 & 2 \\
\hline $\begin{array}{c}\text { Ease of Use } \\
\text { \& Adaptability }\end{array}$ & 3 & 3 & 4 & 1 \\
\hline Cost of System & 2 & 3 & 4 & 1 \\
\hline Limitation & $\begin{array}{l}\text { restricted to low } \\
\text { flow rates }\end{array}$ & $\begin{array}{c}\epsilon<0.15-0.20 \\
\text { small bubbles may } \\
\text { not be detected }\end{array}$ & $\epsilon<0.20$ & $\begin{array}{c}\text { global } \\
\text { measurement }\end{array}$ \\
\hline
\end{tabular}

Numbers in table indicate a ranking on a scale of 1 to 5 . Rank 1 indicates that the technique is most suitable and rank 5 signifies that the technique is not to be preferred. Ranking for the cost of the system is based on 1 representing the least expensive and 5 representing the most expensive system. 
modified as (Euzen et. al. 1993):

$$
\Delta P=\frac{1}{2}\left(\epsilon_{g} \rho_{g} v_{g}^{2}+J \epsilon_{l} \rho_{l} v_{l}^{2}\right)
$$

where $J$ is the phase coupling factor. If the two phase mixture can be considered as pseudohomogeneous, with the velocities of the two phases approximately equal, then $J$ can be set to 1. Otherwise one needs to calculate $J$ based on assumptions concerning the relative velocity between the phases. It is also necessary to know the local holdup at the same point measured at the same instant as the dynamic pressure $\Delta P$. The complexity of data interpretation increases further in gas-liquid-solid systems. Nevertheless, the method has found wide acceptance in industrial circles, inspite of its limitations, but the interpretation is based on simplified treatment of Eq. 22 using assumptions that may not be justified in churn turbulent flows.

The turbine flow meter and its variants, the vane probe and the flywheel anemometer, are all based on measuring the rotational speed induced by the fluid in motion. The implicit assumption is that the momentum of the flowing liquid on the flow meter significantly exceeds that of the flowing gas. Similar to the pitot tube, the use of the method would be limited to low gas flow rates and complexity in the interpretation of measurement increases with the presence of a solid phase. Nottenkamper et. al (1983) have used the flywheel anemometer for liquid velocity measurements in an air-water bubble column.

In hot wire anemometry a small electrical resistance wire or film (supported on some base) is heated and exposed to the flow stream. Due to the removal of heat by the flowing fluid, the resistance changes. This change is a function of the flow velocity and the physical properties of the fluid. Thus, in single-phase flow, the heat flux is directly related to the velocity. The method can be implemented in one of two ways - either the constant resistance (or temperature) mode, or the variable resistance mode. In the constant resistance mode the resistance of the wire or film is held constant, so that the changes in the heat flux due to flow velocity are reflected as voltage changes in the anemometer circuit. In the variable resistance mode, the changes in the current in the circuit are measured. The main problem in using hot wire/film anemometry in two phase flows is the inability to recognize a phase change directly. This calls for some very intelligent signal processing. For example Resch and Leutheusser (1972) identified the phase change by comparing the peak to peak variation of the signal with a given threshold level. The difficulty here is in setting the correct threshold for identifying the phases and consequently there is some arbitrariness involved. The signal delivered by a hot film probe is very spiky owing to the abrupt change in the heat transfer coefficient at the crossing of the phases (Delhaye, 1969). This has been exploited by Michiyoshi and 
Serizawa (1986) who have used a method that is analogous to differential thresholding. The differentiated output signal indicates two distinct peaks corresponding to a bubble coming in contact with the sensor and leaving it. The entire period of time in between the two peaks (probe is in gas phase) is considered as a dead time and is eliminated from the liquid signal. Difficulties still exist due to smaller amplitude peaks corresponding to incomplete piercing or bubble sliding on the probe. In such situations it is diffcult to identify whether the signal is due to a bubble or comes from the liquid phase. Despite all these complexities, the probe has found wide acceptance, since it is probably the most convenient and inexpensive method for the purpose of liquid velocity measurements.

Laser Doppler Velocimetry is considered to be an accurate and reliable method of measuring flow velocities in single phase flow. In a dual beam system two laser beams of equal intensity are focused to cross at a point of interest in the flow field. The measurement volume is a small ellipsoidal region at the intersection of the beams. The fluid is seeded with minute tracer particles which follow the motion of the fluid. When one such particle passes through the control volume, light from each of the beams get scattered and interfere in space. This is seen as a varying intensity fringe pattern by a detector. The electrical signal output from the detector is referred to as a Doppler burst. The particle velocity $U$ is related to the Doppler shift frequency $f_{D}$, the intersection angle between the incident laser beams $\theta$ and the wavelength $\lambda$ of the beams by :

$$
U=\frac{f_{D} \lambda}{2 \sin 0.5 \theta}
$$

Thus, for a given wavelength and angle of intersection of the laser beams, the Doppler shift is directly related to the velocity, and no calibration is required. When a bubble passes through the beam, a large amount of light is scattered, reflected and refracted, some of which reaches the photodetector. It is necessary to set up the LDV processor so that the light scattered by a bubble is not interpreted as the liquid phase velocity. The signal is rejected if it is above a certain amplitude. If the test section to be investigated is large, difficulties also arise due to the interruption of the laser beam outside the measuring volume. Satisfactory measurements of the instantaneous velocity components can be made for void fractions of less than $10 \%$ provided that the signal is adequately processed to reject the noise due to reflection of the light by the bubbles (Lance and Bataille, 1991)

Tsuji and Morikawa (1992) have used LDV for the simultaneous measurement of the velocities of both phases in an air-solid two phase flow in a horizontal pipe. Solid particle sizes were of the order of a millimeter to a hundred microns. The particles used for seeding the gaseous phase were much smaller. The intensity of the scattered signal from the large 
particles is stronger than from those used for seeding the air. The identification of the signals from these two kinds of particles was thus based on the amplitude of the signal. The difficulty is that the amplitude of the signal obtained due to a particle that intersects the measuring volume partially is a source of noise. However, most often the amplitudes for these partial intersections are in between the two extremes of the signal amplitudes corresponding to the solid phase particles and the seed particles. Thus, only the signals corresponding to these two extremes are retained and the rest are eliminated. This method is probably suitable for measuring the solids velocity in a Fischer-Tropsch system with moderate (15 to $20 \%$ by weight) solids loading. For larger particle sizes the Doppler burst drops out completely (at least in the forward scattering mode) and hence LDV cannot be used to obtain the flow velocity of such solids.

In analogy to tracer techniques used for measurement of the residence time distribution of a phase in a reactor, Lubbert and Larson (1990) have developed a tracer technique for measurement of not only the local liquid phase velocity but also the mixing behavior. The method relies on using heat instead of electrolytes or dyes as the tracer. Fluid elements are tagged by direct local ohmic heating using a high frequency alternating current between two small electrodes introduced inside the reactor. The dispersion of heat is measured at a small distance away from the source of heat using a hot-film anemometer switched as a temperature detector. The distance between the transmitter and receiver can be varied in an interval of 2 to $20 \mathrm{~cm}$. The signal to noise ratio of the device is increased by using input signals in the form of a pseudo-random sequence rather than as a series of identical pulses. The information concerning the time of flow distribution is obtained from the cross-correlation between the input and output signals. A schematic of the probe is illustrated in Fig. 13. A probability density function (p.d.f.) is assumed for the number of tracer particles at a given distance from the source, at a given instant of time after injection. This distribution is assumed to be normal. A nonlinear fit of the measured time of flow data to the assumed p.d.f. provides the mean time of flow as well as certain other parameters related to the local dispersion. From the mean time of flow and the distance between the sensors the local liquid phase velocity can be estimated. Indeed the method is rather elegant for measuring local velocities with the added advantage of obtaining information on local dispersion as well. Unlike the other intrusive probes, it does not have the problems of signal processing associated with phase change and partial intersection of a bubble with the measuring device. It is however, not clear as to how the system would respond if the fluids involved are already at an elevated temperature. Its application to three phase system has not been tested.

In addition to the kind of techniques described above, there are methods for velocity measurements that can be grouped under flow visualization. Particle Image Velocimetry 


\section{Resistance Thermometer}

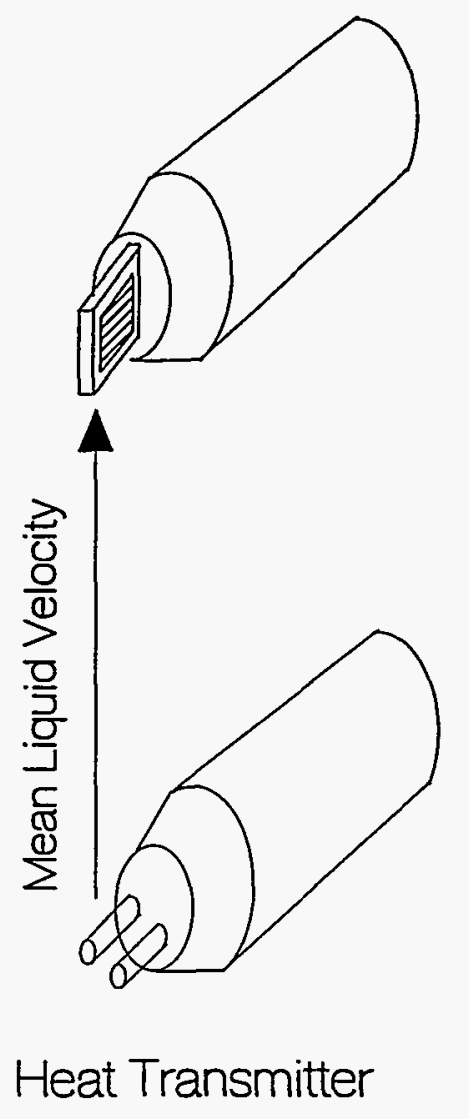

Figure 13: Arrangement of probes for the heat pulse technique

(PIV) (Adrian, 1991) in its simplest form uses a sheet of laser light to illuminate a section of the flow and images of small scattering (tracer) particles are photographed at right angles to the sheet. The scattering particles used are very small, of the order 10 to 20 microns, and consequently the laser source used must have high energy to ensure adequate scattering. The concentration of the particles used corresponds to volume fraction of the order of $10^{-8}$ to $10^{-5}$ and consequently does not affect the fluid rheology. The velocity field in the plane of the imaged sheet is measured by recording a series of exposures and extracting the mean displacement of the particle image between successive exposures. A problem arises if the first or second image of a particle is not recorded because its trajectory carries it out of the illuminated plane. Similar to other optical techniques, PIV is restricted to relatively transparent media. Thus, the concentration of suspended solids (if one of the phases is a solid) has to be low. Even if one resorts to refractive index matching of the solid and the 
liquid phase, high concentrations of the solids would mean a reduction in the transmission of the scattered light. The use of PIV techniques to bubble columns and gas-liquid-solid fluidized beds has been advocated by L. S. Fan and his group at the Ohio State University (Tzeng et. al. 1993).

A technique which is similar to PIV is Laser Induced Photochemical Anemometry (LIPA) in which the liquid and/or the solid phase is doped with photoexcitable chemicals which, upon excitation by a beam of laser, enables the identification of points in the flow. The laser highlighted regions are imaged at successive times, in a manner similar to PIV, and from their displacement by the flow, information concerning the velocity field can be inferred. Falco and Nocera (1991) contend that, unlike PIV, the technique does not have reflected light problems and is also relatively insensitive to refractive index mismatch. The system is applicable to studies of flows with suspended solids by using photoactive solid particles seeded into the flow. The LIPA technique is rather new and is still undergoing development. It might be a method for measuring the solid phase velocities in very densely suspended flows. It has been demonstrated to measure the phase velocities in a liquid-solid flow with $33 \%$ solids loading by volume. However, it is a rather expensive method and also one needs to find specific chemicals for flow velocities and fluids of interest. Very specific light sources are needed as well. Consequently, one cannot recommend it for use in a system such as the Laporte reactor. It is probably a good system to work with within the confines of a laboratory.

Finally, we review the technique that we work with in our Chemical Reaction Engineering Laboratory (CREL) at Washington University in St. Louis. Radioactive tracing has been used in industry for residence time distribution (RTD) measurements in reactors. The Computer Automated Radioactive Particle Tracking (CARPT) facility in our laboratory is an extension of that principle. A single radioactive particle of size and density designed to match the properties of the phase to be traced (solids in gas or liquid fluidized beds, liquid in gas-liquid bubble columns) is introduced into the flow. Instantaneous particle position is identified by the simultaneous monitoring of the radiation intensities received at a set of $\mathrm{NaI}$ detectors located strategically around the column. For a given operating condition of the flow, the particle motion is continuously tracked for long periods of time. Pre-established calibration curves for radiation intensity versus distance for each detector are then used in a linear regression scheme to determine the position of the particle at each sampling instant. Time differentiation of this position data yields instantaneous velocities and accelerations of the particle. To infer the flow field from this, the flow domain is divided into a set of compartments and the calculated instantaneous velocities are assigned to the compartment in which the particle resides at that instant of time. Each compartment ultimately has a large 
number of such assignments corresponding to the data collected over the period of investigation during which the system is operated at steady state. Invoking the ergodic hypothesis, an ensemble average of all such velocities in a compartment yields the average velocity for each of the compartments in the flow. The instantaneous and time averaged velocities can then be used to determine various turbulence parameters of interest. The hardware and software developed for CARPT is described by Devanathan (1991), Moslemian et. al. (1992) and Yang (1992). The accuracy of the system is dependent on the accuracy of the calibration in the distance and intensity relation for the detectors. This in turn is dependent on the accurate positioning of the tracer at known locations within the reactor. The requirement of an accurate calibration is a major drawback of the technique. In addition, it also appears that one needs to match the particle density to the dynamic density of the dispersion rather than that of the fluid itself. Like the LIPA it is also a method that can be implemented and used conveniently only within a laboratory or a pilot plant.

Some of the techniques mentioned above for the measurement of liquid phase velocities can also be adopted for the measurement of solid particle velocities. The laser velocimetry and particle image velocimetry methods are applicable for solids velocity measurements in system with relatively small solids loading, generally about 15 to $20 \%$. With higher solids concentration the attenuation and scattering of the light beam or sheet leads to problems in the interpretation of the signal. The radioactive particle tracking technique is ideally suited for the measurement of solids velocities.

Apart from these sophisticated and powerful methods there few relatively simple techniques for measurement of solids velocities. A technique that could possibly be used in an industrial system is the one based on the intercorrelation of signals from two identical sensors that are placed a small distance apart. The time delay in the measured quantity between the sensors represents the time required for the information to propagate from one sensor to the other. If $s_{1}(t)$ is the measured signal at the first probe and $s_{2}(t+\tau)$ is the measured quantity at the downstream probe at time $(t+\tau)$, the cross-correlation is defined as

$$
C(\tau)=\frac{\int_{0}^{T} s_{1}(t) s_{2}(t+\tau)}{\int_{0}^{T} s_{1}^{2}(t) d t}
$$

where the averaging is performed over a sufficiently long period of time $T$. A plot of $C(\tau)$ with respect to $\tau$ provides the most likely value of the transit time $\tau_{m}$ between the two probes. With the distance between the two sensors known the velocity can then be calculated.

For the application of this technique it is necessary that the sensors used are highly sensitive and rapid. Typically used sensors are capacitance and optical probes, the principles 
of operation of both having been discussed earlier. With the capacitance probes the variation on the dielectric permittivity is measured at two points slightly apart form each other, in the main flow direction. The signals from the two probes are examined by a correlator. Optical fiber probes can similarly be used but the application is limited to dilute systems, since in dense or opaque media the absorption of light disturbs the measurement and the light that is reflected or backscattered must be taken into account. In addition, these probes are very fragile. Most often the distance between the sensors has to be optimized for a given range of velocities to be measured.

Recommendation : Once again the choice of a method is rather difficult. It is our opinion that it is best to choose a couple of simple methods and obtain a measure of their performance in simpler laboratory conditions by comparing the results with those obtained by more accurate methods. This would provide some estimate of the errors that might be involved when using a simpler technique in the actual reactor. For example, we could compare the results from a pitot tube with say that from hot wire anemometry in an air-water flow in the laboratory. Based on some theoretical assumptions for the flow conditions prevailing, it might be possible to estimate the phase coupling factor required for the use of the pitot tube in three phase systems. Depending on the flow conditions (such as solids loading, superficial gas velocity etc). it might even be possible to use hot film anemometry or the heat pulse probe of Lubbert. Considering the difficulty involved in making velocity measurements in the actual system, it might be best to make measurements of the centerline velocities using a pitot tube that has been suitably calibrated for the presence of solids. Table 5 provides a comparison of the characteristics of the available methods for phase velocity measurement.

\section{Final Recommendations and Remarks}

The presently available instrumentation for measurement of the fluid dynamic parameters are by and large cumbersome to be used in a slurry bubble column on the scale of a pilot plant. However, some gross features of the flow in such a system are still measurable. The measurement of the overall gas holdup can be achieved by means of the bed expansion method and/or by pressure drop measurement. The bed expansion can be conveniently measured by using the $\gamma$ densitometer already in use at Laporte. It is also recommended to install a series of pressure taps along the column height which would enable the measurement of the sectional holdup in the system. They can also be used in the estimation of bubble sizes by means of the dynamic gas disengagement technique. Installation of an Americium - 241 source in addition to the Cesium - 137 source is also recommended to provide some 
Table 5: Utility of Different Techniques for Liquid Velocity Measurement

\begin{tabular}{|c|c|c|c|c|c|c|}
\hline & Pitot Tube & $\begin{array}{c}\text { Hot Wire/Film } \\
\text { Anemometry } \\
\end{array}$ & LDV & $\begin{array}{c}\text { Heat Pulse } \\
\text { Probe }\end{array}$ & PIV & CARPT \\
\hline Intrusiveness & 5 & 4 & 1 & 4 & 1 & 1 \\
\hline $\begin{array}{l}\text { Applicability in } \\
\text { Aqueous Systems }\end{array}$ & Yes & Yes & Yes & Yes & Yes & Yes \\
\hline $\begin{array}{c}\text { Applicability in } \\
\text { Hydrocarbon Systems } \\
\end{array}$ & Yes & Yes & Yes & Yes & Yes & Yes \\
\hline $\begin{array}{l}\text { Applicability in } \\
\text { 3-Phase systems }\end{array}$ & 4 & 2 & 3 & 3 & 3 & $\begin{array}{l}4 \text { (liquid phase) } \\
1 \text { (solid phase) }\end{array}$ \\
\hline $\begin{array}{c}\text { Applicability in } \\
\text { corrosive, high } \\
\text { pres./temp. systems }\end{array}$ & 5 & 4 & 1 & 3 & 1 & 1 \\
\hline Accuracy & 4 & 3 & 1 & 3 & 2 & 2 \\
\hline $\begin{array}{c}\text { Ease of Use } \\
\text { \& Adaptability }\end{array}$ & 1 & 2 & 2 & 2 & 5 & 5 \\
\hline Cost of System & 1 & 2 & 3 & 2 & 5 & 5 \\
\hline Limitation & $\begin{array}{l}\text { restricted to } \\
\text { low flow rates }\end{array}$ & $\begin{array}{l}\text { restricted to } \\
\text { low flow rates }\end{array}$ & $\epsilon<0.15-0.20$ & $\begin{array}{l}\text { indirect velocity } \\
\text { measurement }\end{array}$ & $\begin{array}{c}\epsilon<0.2 \\
\text { refractive index } \\
\text { matching required }\end{array}$ & $\begin{array}{c}\text { cumbersome } \\
\text { procedure, but } \\
\text { provides unique data }\end{array}$ \\
\hline
\end{tabular}

Numbers in table indicate a ranking on a scale of 1 to 5 . Rank 1 indicates that the technique is most suitable and rank 5 signifies that the technique is not to be preferred. Ranking for the cost of the system is based on 1 representing the least expensive and 5 representing the most expensive system. 
chordal average measurements of the solids holdup by means of dual energy densitometry principles. Measurement of centerline phase velocity can also be accomplished by means of a suitably calibrated pitot tube. Tests on using the heat pulse probe of Lubbert to provide some measure of the velocity of the phases is also recommended. 


\section{Nomenclature}

c

C

$d$

$D_{c}$

$f$

$f_{D}$

$g$

$h$

$H_{0}$

$H_{g}$

I

$I_{\circ}$

$J$

$k$

$l$

$l_{g}$

$m$

$P$

$r$

$R$

$t$

$U_{l}$

$U$

$x$

$z$

Greek Symbols

$\epsilon$

$\epsilon_{s}$

$\bar{\epsilon}$

$\epsilon_{c}$

$\kappa$

$\lambda$ constant

cross-correlation

distance

column diameter

friction factor

Doppler shift frequency

acceleration due to gravity, $\mathrm{m} / \mathrm{s}^{2}$

axial coordinate

static height of the single (liquid) or

two phase (liquid + solid) system

height of two or three phase dispersion in the column

transmitted intensity of radiation

intensity of radiation at source

two phase flow coupling parameter

dielectric constant

total path length of radiation in a mixture of phases, $m$

chord length of bubble

power law exponent in equation for radial variation of holdup

pressure

radial position

radius of test section

time

liquid superficial velocity

particle velocity

position

height of liquid in manometer

gas holdup, volume fraction of the column occupied by gas

solids holdup

cross-sectional mean holdup

void fraction at the center of the test section

di-electric constant

wavelength 


$\begin{array}{ll}\mu & \text { mass attenuation coefficient } \\ \xi & \text { dimensionless position } \\ \rho_{l} & \text { liquid or slurry density } \\ r h o_{g} & \text { gas density } \\ \tau & \text { time delay } \\ \tau_{w} & \text { shear stress } \\ \theta & \text { angle }\end{array}$

\section{Subscripts}

$g$

$l$

$m t$

$t p$ gas phase

liquid phase

empty test section

two phase 


\section{References}

Abuaf, N., Wilkins Jr, B., and Ward, H. C., 1979, Radio Frequency Probe for Bubble Size and Velocity Measurements, Rev. Sci. Instruments, 50, 1260-1263.

Adrian, R. J., 1991, Particle Imaging Techniques for Experimental Fluid Mechanics, Annual Reviews of Fluid Mechanics, 23, 261-304.

Banerjee, S., and Lahey, R. T., 1981, Advances in Two-Phase Flow Instrumentation in Advances in Nuclear Science and Technology, 13, Plenum Press, New York.

Barr, W. L., 1962, Method for Computing the Radial Distribution of Emitters in a Cylindrical Source, J. Opt. Soc. Am., Vol. 52, No. 8, pp. 885-888.

Berger, F. P., and Ziai, A., 1983, Optimization of Experimental Conditions for Electromechanical Mass Transfer Measurements, Chem. Eng. Res. Dev., 61, 373.

Bockasten, K., 1961, J. Opt. Soc. Am., Vol. 51, pp. 943.

Broring, S., Fischer, J., Korte, T., Sollinger, S., and Lubbert. A., 1991, Flow Structure of the Dispersed Gas Phase in Real Multiphase Chemical Reactors Investigated by a New Ultrasound-Doppler Technique, Can. J. Chem. Eng. 69, 1247-1256.

Buchholz, R., Zakrzewski, W., and Schugerl, K., 1981, Techniques for Determining the Properties of Bubbles in Bubble Columns, Int. Chem. Eng. 21, 180-187.

Burgess, J. M., and Calderbank, P. H., 1975, The Measurement of Bubble Parameters in Two Phase Dispersions, I : The Development of an Improved Probe Technique, Chem. Eng. Sci., 30, 743-750.

Bukur, D. B., Daly, J. G., and Patel, S., 1996, Application of a Gamma-Ray Attenuation for Measurement of Gas-Holdups and Flow Regime Transitions in Bubble Columns, to be published in Ind. Eng. Chem. Res.

Cheremisinoff, N. P., 1986, A Review of Experimental Methods for Studying the Hydrodynamics of Gas-Solid Fluidized Beds, Ind. Eng. Chem. Process Des. Dev., 25, 329-351.

Cimorelli, L., and Evangelistic, R., 1967, The Application of the Capacitance Method for Void Fraction Measurement in Bulk Boiling Conditions, Int. J. Heat and Mass Trans. 10, 277-288.

Clark, K. N., and Foster, N. R., 1987, Application of Neutron Technique to Studies of Reactor Fluid Dynamics, Chem. Eng. J. 34, 35-46. 
Colombo, A., Hassid, A., and Premcoli, A., 1967, Density Measurements in Heated Channels at High Pressure by Means of a Quick Closing Valve Method, Energy Nucleare, 15 119-128.

Deckwer, W. D., Burckhart, R., and Zoll, G., 1974, Mixing and Mass Transfer in Tall Bubble Columns, Chem. Eng. Sci., 29, 2177-2188.

Deckwer, W. D., Lousi, Y., Zaidi, A., and Ralek, 1980, Hydrodynamic Properties of the Fischer Tropsch Slurry Process, Ind. Chem. Eng. Proc. Des. Dev., 19, 699-708.

Deckwer, W. D., Schumpe, A., Nguyen-Tien, K., and Serpemen, Y., 1982, Oxygen Mass Transfer into Aerated C.M.C. Solutions in a Bubble Column, Biotech. and Bioeng. 2, 461481.

De-Lasa, H., Lee, S. L. P., and Bergougnou, M. A., 1984, Bubble Measurement in Three Phase Fluidized Beds using a U-Shaped Optical Fiber, Can. J. Chem. Eng. 62, 165-169.

Delhaye, J. M., 1969, Hot Film Anemometry in Two Phase Flow, in Two Phase Flow Instrumentation, 11th National ASME/AIChE Heat Transfer Conference, Minneapolis, 58-69.

Delhaye, J. M., Semeria, J., and Flammand, J. C., 1973, Void Fraction and Vapor and Liquid Temperatures : Local Measurements in Two Phase Flow Using a Microthermocouple, J. Heat Transfer, Trans. A.SME, 95, 365-370.

Devanathan, N., Moslemian, D., and Duduković, M. P., 1990, Flow Mapping in Bubble Columns, Using CARPT, Chem. Eng. Sci., 45, 2285.

Dickin, F. J., Williams, R. A., and Beck, M . S., 1993, Determination of Composition and Motion of Multicomponent Mixtures in Process Vessels Using Electrical Impedance Tomography - I. Principles and Process Engineering Applications, Chem. Emg. Sci., 48, 1883-1897.

Dong, J., and Kearney, R. J., 1991, "Symmetrizing, Filtering, and Abel Inversion using Fourier Transform Techniques", J. Quant. Spectrosc. Radiat. Transfer, Vol. 46, No. 3, pp. 141-149.

Euzen, J. P., Trambouze, P., and Wauquier, J. P., 1993, Scale-Up Methodology for Chemical Processes, Editions Technip, Paris.

Falco, R., and Nocera, D., 1992, Quantitative Multipoint Measurements and Visualization of Dense Liquid-Solid Flows Using Laser Induced Photochemical Anemometry (LIPA), in 
Particulate Two Phase Flow, Ed: Rocco, M.C., Butterworth-Heinemann, Boston.

Geary, N. W., 1991, On Bubble Columns, Ph. D. Thesis, Louisiana State University. Greaves, M., and Kobbacy, K. A. H., 1984, Measurement of Bubble Size Distribution in Turbulent Gas-Liquid Dispersions, Chem. Eng. Res. Des., 62, 3-12.

Groen, J. S., Mudde, R. F., and Van den Akker, H. E. A., 1995, Time dependent behavior of the flow in bubble column, Trans. I. Chem. Engrs., 73, 615-621.

Hewitt, G. F., 1978, Measurement of Two Phase Flow Parameters, Academic press, New York.

Hilgert, W., and Hofmann, H., 1986, Characterization of Gas Phase Flow in Bubble Columns at Low Superficial Gas Velocities with the Aid of Ultrasonic Doppler Technique, Ger. Chem. Eng. 9, 180-190.

Hills, J. H., 1976, The Operation of a Bubble Column at High Throughputs I. Gas Holdup Measurements, Chem. Engg. J. 12, 89-99.

Idogowa, K., Ikeda, K., Fukuda, T., and Morooka, S., 1986, Behavior of Bubbles of the Air-Water System in a Column under High Pressure, Int. Chem. Engg. 26, 468-474. 3, 89-116.

Johansen, G. A., Froystein, T., Hjertaker, B. T., Isaksen, O., Olsen, O., Strandos, S. K., Skoglund, T. O., Abro, E., and Hammer, E. A., The Development of a Dual Mode Tomograph for Three-Component Flow Imaging, 1995, Chem. Engg. J., Vol. 56,

Kumar, B. S., Computed Tomographic Measurements of Void Fraction and Modeling of the Flow in Bubble Columns, Ph.D. Thesis, Florida Atlantic University, December, 1994.

Kumar, B. S., Moslemian, D., and Duduković, M. P., 1995, A $\gamma$ Ray Tomographic Scanner for Imaging Voidage Distribution in Two Phase Flow Systems, Flow. Meas. Instrum., Vol. 6, No. 1, pp. 61-73.

Lance, M., and Bataille, J., 1991, Turbulence in the Liquid Phase of a Uniform Bubbly Air Water Flow, J. Fluid Mech., 222, 95-118.

Landau J., Boyle, J., Gomaa, H. G., and Al Taweel, A. M., 1977, Can. J. Chem. Eng., 1977, $55,13$.

Louge, M., and Opie, M., 1990, Measurement of the Effective Di-electric Permittivity of Suspensions, Powder Technology, 62, 85-94. 
Lubbert, A., Korte, T., and Larson, B., 1987, Simple Measuring Techniques for the Determination of Bubble and Bulkphase Velocities in Bioreactors, Appl. Biochem. Biotechnol. 14, 207-219.

Lubbert, A., and Larson, B., 1990, Detailed Investigations of the Multiphase Flow in Airlift Tower Loop Reactors, Chem. Eng. Sci., 45, 3047-3053.

MacTaggart, R. S., Nasr-El-Din, H. A., and Masliyah, J. H., 1993, A Conductivity Probe for Measuring Local Solids Concentration in a Slurry Mixing Tank, Sep. Tech., 3, 151-160.

Matsura, A., and Fan, L. S., 1984, Distribution of Bubble Properties in a Gas-Liquid-Solid Fluidized Bed, AIChE J., 6, 894-903.

Merchuk, J. C., and Stein, Y., 1981, Local Holdup and Liquid Velocity in Airlift Reactors, AIChE J. 27, 377-388.

Merchuk, J. C., 1986, Gas Holdup in and Liquid Velocity in a Two Dimensional Air Lift Reactor, Chem. Eng. Sci., 41, 11-16.

Michiyoshi, I., and Serizawa, A., 1986, Turbulence in Two Phase Bubbly Flow, Nucl. Eng. Des. 95, 253-267.

Mitchell, J., and Hanratty, T. J., 1966, A Study of Turbulence at a Wall Using an ElectroChemical Wall Shear Stress Meter, J. Fluid Mech., 26, 199-221.

Moslemian, D., Devanathan, N., and M. P. Duduković, 1992, A Radioactive Particle Tracking Facility for Investigation of Phase Recirculation in Multiphase Systems, Rev. Sci. Instrs. $63,4361-4372$.

Moujaes, S., and Dougall, R. S., 1987, Experimental Investigation of Cocurrent Two Phase Flow in a Vertical Rectangular Channel, Can. J. Chem. Eng., 65, 705-715.

Nakoryakov, V. E., Kashinsky, O. N., and Kozmenko, B. K., 1984, Electrochemical Method for Measuring Turbulent Characteristics of Gas-Liquid Flows, in Measuring Techniques in Gas-Liquid Two Phase Flows, Ed : Delhaye, J. M. and Cognet, G., Springer-Verlag, Berlin.

Nasr-El-Din, H., Shook, C. A., and Colwell, J., 1987, A Conductivity Probe for Measuring Local Concentrations in Slurry Systems, Int. J. Multiphase Flow, 13, 365-378.

Nassos, G. P., and Bankoff, S. G., 1967, Slip Velocity in an Air-Water System under Steady State and Transient Conditions, Chem. Eng. Sci. 12, 661. 
Nicol, R. S., and Davidson, J. F., 1988, Gas Holdup in Circulating Bubble Columns, Che. Engg. Res. Des. 66, 152-158.

Nottenkamper, R., Steiff, A., and Weinspach, P. M., 1983, Experimental Investigation of Hydrodynamics of Bubble Columns, Ger. Chem. Engng., 6, 147-155.

Okamura, S., Uchida, S., Katsumata, K., and Iida, K., Measurement of Solids Holdup in a Three Phase Fluidized Bed by an Ultrasonic Technique, Chem. Eng. Sci. 44, 196-197.

Patel, S., Daley, J. G., and Bukur, D. B., 1989, Holdup and Interfacial Measurements Using Dynamic Gas Disengagement, AIChE J., 35, 931-942.

Pilhofer, T., 1974, Chem. Ing. Tech. 46, 913.

Prakash, A., and Briens, C. L., 1990, Porous Gas Distributors in Bubble Columns. Effect of Liquid Presence on Distributor Pressure Drop. Effect of Startup Procedure on Distributor Performance, Can. J. Chem. Eng. 68, 204-210.

Reilly, I. G., Scott, D. S., De Bruijn, T., Jain, A., and Piskorz, J., 1986, A Correlation for Gas Hold-Up in turbulent Coalescing Bubble Columns, Can. J. Chem. Eng., 68, 204-210.

Resch, F. J., and Leutheusser, H. J., 1972, Reynolds Stress Measurement in Hydraulic Jumps, J. Hydraul. Res. 10, 409-430.

Riley, A. C., and Louge, M., 1989, Quantitative Capacitance Measurements of Voidage in Gas-Solid Flows, Part. Sci. Tech.7, 51-59.

Rosehart, R. G., Rhodes, E., and Scott, D. S., 1975, Studies of Gas-Liquid (Non-Newtonian) Slug Flow : Void Fraction Meter, Void Fraction and Slug Characteristics, Chem. Eng. J. $10,57-64$.

Sasaki, H., Matsukawa, H., Usui, S., and Matijevic, E., 1986, A New Method for Measuring the Size Distribution of Gas Bubbles in Aqueous Media, J. Colloid and Interface Sci., 113, 500-502.

Schrock, V. E., 1969, Radiation Attenuation Techniques in Two phase Flow Measurements, in Two Phase Flow Instrumentation, 11th National ASME/AIChE Heat Transfer Conference, Minneapolis, 24-35.

Schumpe, A., and Grund, G., 1986, The Gas Disengagement Technique for Studying Gas Holdup Structure in Bubble Columns, Can. J. Chem. Eng., 64, 891-896.

Shah, Y. T., Kelkar, B. G., Godbole, S. P., and Deckwer, W. D., 1982, Design Parameter 
Estimations for Column Reactors, AIChE J., 28, 353-379.

Snoek, C. W., 1988, A Review of Recent Advances in Multiphase Flow Measurements and Methods, in Experimental Heat Transfer, Fluid Mechanics and Thermodynamics, 59-71, Elsevier, New York.

Soong, Y., Gamwo, I. K., Blackwell, A. G., Schehl, R. R., and Zarochak, M. F., 1996, Solids Concentration Measurements in a Three Phase Reactor by an Ultrasonic Technique, Chem. Eng. J.

Sriram, K., and Mann, R., 1977, Dynamic Gas Disengagement : A New Technique for Assessing the Behavior of Bubble Columns, Chem. Eng. Sci., 32, 571.

Steinemann, J., and Buchholz, R., 1984, Application of an Electrical Conductivity Microprobe for the Characterization of Bubble Behavior in Gas-Liquid Bubble Flow, Part. Charact. 1, 102-107.

Stravs, A. A., and Stockar, U. V., 1985, Measurement of Interfacial Areas in Gas-Liquid Dispersion by Ultrasonic Pulse Transmission', Chem. Eng. Sci., 40, 1169-1175.

Tzeng, J. W., Chen, R. C., and Fan, L. S., 1993, Visualization of Flow Characteristics in a 2-D Bubble Column and 3 Phase Fluidized Bed, AIChE, J., 39, 733-744.

Tsouris, C. L., Tavlarides, L., and Bonnet, J. C., 1990, Application of the Ultrasonic Technique for real Time Holdup Monitoring for the Control of Extraction Columns, Chem. Eng. Sci., 45, 3055-3062.

Tsuji, Y., Morikawa, Y., and Shiomi, H., 1984, LDV Measurements of an Air-Solid TwoPhase Flow in a Vertical Pile, J. Fluid Mech., 139, 417.

Ueyama, K., Morooka, S., Koide, K., Kaji, H., and Miyauchi, T., 1980, Behavior of Gas Bubbles in Bubble Columns, Ind. Eng. Chem. Proc. Des. Dev. 19, 592-599.

Vermeer, D. J., and Krishna, R., 1981, Hydrodynamics and Mass Transfer in Bubble Columns Operating in the Churn-Turbulent Regime, Ind. Eng. Chem. Proc. Des. Dev. 20, 475-482.

Wolf, J., 1988, Investigation of Bubbly Flow by Ultrasound Tomography, Part. Part. Syst. Charact., 5, 170-173.

Xie, C. G., Huang, S. M., Hoyle, B. S., Thorn, R., Lenn, C., Snowden, D., and Beck. M. S., 1992, Electrical Capacitance Tomography for Flow Imaging : System Model for Devel- 
opment of Image Reconstruction Algorithms and Design of Primary Sensors, IEEE. Proc., 139, 89-98.

Xie, C. G., Reinecke, N., Beck, M. S., Mewes, D., and Williams, R. A., 1995, Electrical Tomography Techniques for Process Engineering Applications, The Chemical Engineering Journal, Vol. 56, pp. 127-133.

Yamaguchi, K., and Yamazaki, Y., 1982, Characteristics of Countercurrent Gas-Liquid Two Phase Flow in Vertical Tubes, J. Nucl. Sci. Tech. 19, 985-996.

Yasunishi, A., Fukuma, M., and Muroyama, K., 1986, Measurement of the Behavior of gas Bubbles and Gas Holdup in a Slurry Bubble Column by a Dual Electroresistivity Probe Method, J. Chem. Engg. Japan, 19, 444-448.

Zun, I., and Saje, F., 1982 Statistical Characteristics of Bubble Flow, p. 112, in : Proc. 3rd Austrian-Italian-Yugoslavian Chem. Eng. Conf., 2, Graz. 